\title{
INTERIOR INSULATION FOR WALL RETROFITTING - A PROBABILISTIC ANALYSIS OF ENERGY SAVINGS AND HYGROTHERMAL RISKS
}

\author{
EVy VerEeCKEN ${ }^{1}$, LIESJe VAN GELDER ${ }^{2}$, HANS JANSSEN ${ }^{3}$ AND StAF RoELS ${ }^{4}$
}

1 KU Leuven, Building Physics Section, Kasteelpark Arenberg 40, B-3001 Leuven, Belgium, +32 16321098

Evy.Vereecken@bwk.kuleuven.be

2 KU Leuven, Building Physics Section, Kasteelpark Arenberg 40, B-3001 Leuven, Belgium

Liesje.VanGelder@bwk.kuleuven.be

${ }^{3}$ KU Leuven, Building Physics Section, Kasteelpark Arenberg 40, B-3001 Leuven, Belgium

Hans.Janssen@bwk.kuleuven.be

${ }^{4}$ KU Leuven, Building Physics Section, Kasteelpark Arenberg 40, B-3001 Leuven, Belgium

Staf.Roels@bwk.kuleuven.be

\section{ABStRACT}

Interior insulation is often the only possible post-insulation technique to improve the thermal performance of single leaf masonry walls. As a result of potential damage patterns such as frost damage, interstitial condensation and mould growth however, there is often some reluctance to adopt this technique. To fully exploit the capacity for energy savings offered by interior insulation while avoiding hygrothermal failure, a reliable risk assessment is extremely important. This requires a probabilistic 
Postprint: Vereecken E, Van Gelder L, Janssen H, Roels S, 2015. Interior insulation for wall retrofitting - A probabilistic analysis of energy savings and hygrothermal risks. Energy and Buildings 89: 231-244. doi.org/10.1016/j.enbuild.2014.12.031

approach, since the uncertainty of all influencing parameters might result in widely varying results.

As, so far, no real methodology is available to select the interior insulation system and thickness resulting in the best balance between energy savings and hygrothermal risks, this paper presents a decision tool based on a Monte Carlo analysis. Additionally, the influence of the rain load and some masonry characteristics is discussed. In the study, both vapour tight interior insulation systems and a capillary active insulation system are considered. Overall, vapour tight systems tend to be preferable for structures that are resistant to frost damage. For buildings sensitive to frost damage or when wooden beam ends are present, however, capillary active systems are shifted forward.

\section{KEY WORDS:}

Interior insulation, hygrothermal performance, probabilistic assessment, Monte Carlo, energy savings, capillary active insulation, vapour tight insulation

\section{INTRODUCTION}

The MURE overview [1] of energy efficiency policies and measures illustrates the growing efforts to reduce our energy consumption. The building sector is frequently mentioned in this respect, because of its large potential to contribute to that reduction. Indeed, buildings are responsible for approximately $40 \%$ of the world's primary energy use [2], a large share of which stems from our existing building stock. After all, in many countries, a large part of the existing building stock has been built before the first energy crisis. The growing awareness of their high energy use as well 
Postprint: Vereecken E, Van Gelder L, Janssen H, Roels S, 2015. Interior insulation for wall retrofitting - A probabilistic analysis of energy savings and hygrothermal risks. Energy and Buildings 89: 231-244. doi.org/10.1016/j.enbuild.2014.12.031

as poor comfort has led to a progressively increasing renovation and retrofitting of old buildings. And while upgrades of the (thermal) performance of roofs and windows are often the most cost-effective measures [3], the importance of the transmission losses through the walls should not be underestimated. After all, exterior walls cover a large part of the building envelope and therefore play an important role in reducing heat losses as well as in ensuring a healthy indoor environment and an acceptable occupant comfort.

To improve the thermal performance of single leaf masonry walls - in many West and Central European countries the most common construction technique until the Second World War - interior or exterior insulation can be applied. The latter technique is by far the most efficient measure. However, for buildings in an urban context, historical buildings or valuable facades [4][5], interior insulation remains the only feasible post-insulation technique. Applying interior insulation will however significantly modify the hygrothermal performance of the wall and, as a consequence, may induce a risk on interstitial condensation [6], frost damage, mould growth and other damage patterns [7]. To reduce the risk on these damage patterns, nowadays some more innovative interior insulation systems are promoted [5][8][9][10]. These systems aim at diminishing the moisture storage in the wall structure by still allowing an inward drying.

In the current study, two novel techniques - a capillary active insulation system [5] using calcium silicate board, and a mineral wool combined with a smart vapour retarder [8] - are compared to two standard systems - a vapour tight XPS-system and a mineral wool combined with a traditional vapour barrier. The analyses focuses on the hygrothermal performance of these systems during the heating season. With 
Postprint: Vereecken E, Van Gelder L, Janssen H, Roels S, 2015. Interior insulation for wall retrofitting - A probabilistic analysis of energy savings and hygrothermal risks. Energy and Buildings 89: 231-244. doi.org/10.1016/j.enbuild.2014.12.031

respect to capillary active interior insulation systems, Vereecken and Roels [11] revealed a higher sensitivity to small modifications of the boundary conditions than observed for a vapour tight system. Moisture in the calcium silicate board was found to result in a decrease in thermal resistance. Additionally, moisture could be redistributed inward resulting in a higher surface and indoor relative humidity. The study hence concluded that caution is required when the wall assembly is exposed to high wind-driven rain loads, and this particularly for thin masonry walls. These observations were however formulated based on a limited deterministic study, neglecting the inherent uncertainty and variability of involved input parameters. The question thus arises whether a generalisation of these conclusions is allowed. To that aim thus, a probabilistic approach is applied in the current paper, in which the uncertainties of the input parameters are explicitly propagated to the uncertainties of the studied performances. Probabilistic approaches are already frequently applied for energy studies $[12][13][14][15][16]$, and can serve as a decision tool [17][18][19][20][21]. For hygrothermal analyses, however, only few studies are available [22][23]. In the current investigation, a probabilistic approach is applied to define the energy savings and the hygrothermal risks caused by interior insulation. To this aim, a hygrothermal model is used in a Monte Carlo analysis. Based on this probabilistic examination, recommendations on interior insulation are formulated, in particular on the choice between a vapour tight and a capillary active system.

In the following section, the case study is explained more in detail. The studied insulation options and the potential hygrothermal consequences are discussed and the wall characteristics and boundary conditions are specified. In the third section, the applied methodology is described. Here, both the hygrothermal model and the 
Postprint: Vereecken E, Van Gelder L, Janssen H, Roels S, 2015. Interior insulation for wall retrofitting - A probabilistic analysis of energy savings and hygrothermal risks. Energy and Buildings 89: 231-244. doi.org/10.1016/j.enbuild.2014.12.031

probabilistic assessment are addressed. After this, in a fourth section, the results are shown and discussed. Hereto, the hygrothermal performance and risk indicators are shown as a function of the dry thermal resistance of the insulation system. Additionally, the impact of the wind-driven rain load and of the masonry characteristics are discussed. In conclusion, the main findings are summarised and some remarks are drawn.

\section{CASE STUdY}

The probabilistic analysis is performed for a single leaf massive masonry wall outfitted with an interior insulation system. The study will be performed for different wall thicknesses and the walls will be exposed to different exterior and interior climatic conditions. Traditional vapour tight interior insulation systems and two novel systems, i.e. capillary active systems and a mineral wool combined with a vapour retarder, will be compared based on their hygrothermal response. Therefore, for each of these systems, all inherent uncertain variables will be taken into account in a Monte Carlo design approach using the hygrothermal model. Both the model and the design approach will be described in section 3. Such a design approach quantifies the probabilistic distributions of the considered performances for each of the design options by repeating the simulation several times while varying the values of the uncertain variables according to their probability. This study limits to a typical cross section of the wall. So, no construction details such as corners or embedded wooden beam ends are considered. Furthermore, the brick mortar composition of the masonry wall is simplified to a single isotropic brick layer. Hence, the analysis can be completed based on one-dimensional simulations. As shown by Vereecken and 
Postprint: Vereecken E, Van Gelder L, Janssen H, Roels S, 2015. Interior insulation for wall retrofitting - A probabilistic analysis of energy savings and hygrothermal risks. Energy and Buildings 89: 231-244. doi.org/10.1016/j.enbuild.2014.12.031

Roels [24] this approach is acceptable if the wall is exposed to realistic climatic conditions.

In what follows the potential hygrothermal risks and the wall performances (section 2.1), the studied interior insulation systems (section 2.2) and the characteristics and boundary conditions (section 2.3 and 2.4) are described.

\subsection{Hygrothermal risks and performances}

Applying interior insulation will reduce the heat loss through the wall. However, it will also significantly modify the hygrothermal performance of the wall assembly, which might result in a number of hygrothermal risks. Figure 1 schematically indicates the different interfaces and surfaces for a wall assembly with interior insulation together with the corresponding potential hygrothermal risks. A brief description of the different damage patterns for which the risks are analysed in the current study is given in what follows.

Figure 1. Wall composition with hazardous planes indicated.

\section{(1) Frost damage}

The extra vapour diffusion resistance caused by the interior insulation system hinders an inward drying of the wall. Additionally, the lower temperature of the original wall structure results in a decreased drying potential toward the exterior. Hence, by applying interior insulation, the moisture content in the original wall structure will 
Postprint: Vereecken E, Van Gelder L, Janssen H, Roels S, 2015. Interior insulation for wall retrofitting - A probabilistic analysis of energy savings and hygrothermal risks. Energy and Buildings 89: 231-244. doi.org/10.1016/j.enbuild.2014.12.031

increase. This in combination with the lower temperature results in an enlarged risk on frost damage [25]. In the current study, the risk on frost damage will be evaluated based on the number of moist freeze-thaw cycles per year at $0.5 \mathrm{~cm}$ from the exterior brick surface. Such 'moist freeze-thaw cycles' are freeze-thaw cycles that occur in combination with a moisture content in the brick (in this case at $0.5 \mathrm{~cm}$ from the exterior surface) that is high enough to induce frost damage. In this study, a moisture content higher than $25 \%$ of the saturated moisture content is assumed to be critical and thus to entail a risk on frost damage. Note that this percentage is lower than $91.7 \%$, which is often mentioned as the critical degree of saturation [26]. Measurements performed by Mensinga et al. [27] showed, however, potential failure due to freeze-thaw cycles starting from a critical degree of saturation equal to $25 \%$. The freezing and thawing point is assumed to be $-2{ }^{\circ} \mathrm{C}$ (because of, for instance, dissolved salts).

(2) (3) Relative humidity in the construction

The increased moisture content in the masonry wall might damage wooden beam ends in the construction [28][29][30]. In the current study, an indication of this risk is made based on the number of hours that the relative humidity in the masonry at $5 \mathrm{~cm}$ from the insulation system exceeds the critical relative humidity for wood decay, and this in January. For the critical relative humidity for wood decay, a relative humidity equal to $95 \%$ is assumed, which corresponds to the lower limit mentioned in [31]. Note, however, that in the present study solely a rough indication of the risk is made, as a one-dimensional approach - without a wooden beam end - is applied and potential air rotations are neglected. Furthermore, a quantitative analysis of the risk on wood decay demands a reliable prediction model, which is currently not at hand. 
Postprint: Vereecken E, Van Gelder L, Janssen H, Roels S, 2015. Interior insulation for wall retrofitting - A probabilistic analysis of energy savings and hygrothermal risks. Energy and Buildings 89: 231-244. doi.org/10.1016/j.enbuild.2014.12.031

Also interstitial condensation at the interface between the masonry wall and the insulation system might be induced. In the current study, the number of hours that the relative humidity between the masonry wall and the insulation system exceeds $99.9 \%$ is evaluated for January.

(4) Indoor surface relative humidity

At the interior surface a too high relative humidity should be avoided, since this entails a risk on mould growth [32]. Because of the shortcomings and discrepancies in the current mould prediction models resulting in widely varying results [33], in the current study no quantitative indication of the mould growth risk will be determined. Instead, the number of hours in January that the surface relative humidity exceeds $80 \%$, which is the lower limit of the critical relative humidity for mould growth according to [31], is used as a risk indicator.

(5) Indoor relative humidity

To end, the potential influence on the indoor relative humidity should be analysed since it can affect the comfort and health of building occupants. Therefore, the number of hours exceeding $70 \%$ indoor relative humidity in January is evaluated.

Note that in addition to these hygrothermal failures, also summer condensation might be induced. This can occur if the moistened masonry wall is dried by solar radiation and if the vapour resistance of the layer at the room side (e.g. finishing layer, vapour barrier/retarder) is too large. Summer condensation occurs between the insulation material and the finishing layer or vapour barrier/retarder. Since summer condensation is less likely to occur in the studied climates (Essen, Bremerhaven, 
Postprint: Vereecken E, Van Gelder L, Janssen H, Roels S, 2015. Interior insulation for wall retrofitting - A probabilistic analysis of energy savings and hygrothermal risks. Energy and Buildings 89: 231-244. doi.org/10.1016/j.enbuild.2014.12.031

München) and since a reliable investigation of this aspect would require a better knowledge on the indoor conditions during summer, which largely depend on the ventilation behaviour of the building owner, this damage pattern is not further analysed in the current study.

\subsection{Interior insulation options}

Two traditional and two novel interior insulation systems, applied to a massive wall, are compared with respect to their hygrothermal performance. The traditional systems studied in the current work are two types of vapour tight systems: (1) extruded polystyrene (XPS) and (2) mineral wool with a traditional vapour barrier (VB). As an interior finishing layer, a $1 \mathrm{~cm}$ gypsum board is applied to these interior insulation systems. The two novel systems aim an inward drying while avoiding interstitial condensation. Thereto, nowadays often capillary active and hygroscopic insulation systems or the use of a smart vapour retarder are promoted. Capillary active systems might capture over-hygroscopic moisture and redistribute it toward the room [34]. The capillary active interior insulation system applied in the current study comprises a calcium silicate layer (CaSi) which is adhered to the masonry wall with a $4 \mathrm{~mm}$ glue mortar. To take the hydraulic interface resistance between the brick layer and the glue mortar and between the glue mortar and the calcium silicate into account, the hydraulic interface resistance as defined in [35][36] is implemented for the numerical calculations. When using a capillary active insulation system, a $1 \mathrm{~cm}$ plaster layer is applied as interior finishing coat. The second novel interior insulation system consists of mineral wool with a smart vapour retarder (SVR), which is characterised by a humidity-dependent vapour diffusion resistance [37]. During the heating season such a foil aims to avoid interstitial condensation by functioning as a 
Postprint: Vereecken E, Van Gelder L, Janssen H, Roels S, 2015. Interior insulation for wall retrofitting - A probabilistic analysis of energy savings and hygrothermal risks. Energy and Buildings 89: 231-244. doi.org/10.1016/j.enbuild.2014.12.031

conventional vapour retarder, while during the cooling season a drying out is possible. For the latter system, a $1 \mathrm{~cm}$ gypsum board is applied as an interior finishing layer.

The performance of both the traditional and the novel systems is studied for three insulation thicknesses: $2 \mathrm{~cm}, 14 \mathrm{~cm}$ and $30 \mathrm{~cm}$. As a reference, also the performance of a non-insulated massive masonry wall is analysed. Hence, 13 design options (the original wall +4 interior insulation systems, with each 3 possible insulation thicknesses) are analysed. The material properties of the different interior insulation systems and the finishing layers are given in Appendix A.

\subsection{Probabilistic characteristics and boundary conditions}

The wall characteristics and boundary conditions that are thought to be of significant influence for the analysed risks and performances, are considered probabilistic. Table 1 presents these probabilistic wall characteristics and boundary conditions with their assumed distributions. Uniform, normal and discrete distributions are considered.

To deal with variability in climatic conditions, three Test Reference Years of Essen, Bremerhaven and München (Germany) [38][39] are included. The latter city has a continental climate, while the former climates are temperate maritime.

To incorporate uncertainty in the wall conditions, the orientation of the wall and solar absorption are considered, but also the amount of wind-driven rain that reaches the wall and the convective heat surface transfer coefficient, which are less straightforward. As described in [40], the catch ratio relates the wind-driven rain (WDR) intensity on a building to the unobstructed horizontal rainfall intensity. This 
Postprint: Vereecken E, Van Gelder L, Janssen H, Roels S, 2015. Interior insulation for wall retrofitting - A probabilistic analysis of energy savings and hygrothermal risks. Energy and Buildings 89: 231-244. doi.org/10.1016/j.enbuild.2014.12.031

catch ratio is function of the reference wind speed and the horizontal rainfall intensity for a given position on the building facade and for a given wind direction. To reckon with variability in wall position and potential shelters, trees or other buildings in the neighbourhood - meteorological conditions are already captured by the climate year - the catch-ratio profile of the central location of a $10 \times 10 \times 10 \mathrm{~m}^{3}$ building is scaled by dividing by 0.849 (the maximal value for this location) and multiplying with a probabilistic scale factor (Table 1). According to [41], the convective heat transfer coefficient $h_{c}$ is

$$
h_{c}=A U_{10}^{B}
$$

with $U_{10}(\mathrm{~m} / \mathrm{s})$ the wind speed in the undisturbed flow at a height of $10 \mathrm{~m}$ above the ground and B is surface-averaged equal to 0.85 and 0.83 for the windward and leeward side, respectively. Coefficient $A$ is also different for windward (WW) and leeward (LW) side, however they are inversely proportional correlated: higher Aww corresponds to lower Atw. By considering Aww and Atw probabilistic, a wide range of potential locations of the wall is taken into account.

Table 1. Probabilistic parameters and distributions.

The properties of the brick facade are subjected to uncertainty as well. Moreover, a large difference between the wall thickness of historical and traditional buildings can be noticed. Therefore, the thickness is considered uniformly distributed between 15 and $50 \mathrm{~cm}$. To vary in material properties, three brick types [39][42][43] are taken into account of which the main characteristics are listed in Table 2 and Figure 2. 
Table 2. Properties brick types.

Figure 2. a) Moisture retention curve and b) liquid permeability of the three brick types.

Finally, several room conditions are considered. Both living rooms and bedrooms are studied with varying floor areas and number of persons. The room types are differing in their occupancy pattern and corresponding vapour production. The living rooms are occupied between 20:00 and 22:00 in the evening, while the bedrooms between 22:00 in the evening and 06:00 in the morning. Each person has a vapour production of $60 \mathrm{~g} / \mathrm{h}$. When people are absent, the remaining vapour production is assumed to be $10 \mathrm{~g} / \mathrm{h}$. The indoor temperature for both room types are normally distributed with a higher mean temperature for the living room. When the outdoor temperature is higher than the set temperature, the indoor temperature is set equal to the outdoor temperature, with a maximum of $25^{\circ} \mathrm{C}$. The range of air change rates is defined by the Belgian ventilation standard NBN D50-001 [45] based on the room volume. If the outdoor temperature exceeds the indoor set temperature, the air change is doubled. The interior moisture buffering capacity is made probabilistic by varying the hygric inertia per cubic meter of room (HIR*), see Eq.(4). The considered range goes from no buffering elements up to the availability of woollen carpets and wooden bookshelves, as described in [46]. 


\subsection{Deterministic boundary conditions}

The remaining boundary conditions are all ór variables with small variations ór of less importance for the current study. Therefore, these boundary conditions are treated deterministically. An overview of the deterministic boundary conditions is given in Table 3.

Table 3. Deterministic boundary conditions.

\section{METHOdology}

\subsection{Hygrothermal model}

The hygrothermal performance of the different wall assemblies is studied by use of HAMFEM [47], an in-house program code that solves the equations for energy and mass conservation based on a finite element method:

$$
\begin{gathered}
\left(c_{0} \rho_{0}+c_{l} w\right) \frac{\partial T}{\partial t}+\left(c_{l} T \frac{\partial w}{\partial p_{c}}\right) \frac{\partial p_{c}}{\partial t}=\nabla\left(\lambda \nabla T-c_{l} T g_{l}-\left(c_{v} T+L_{v}\right) g_{v}\right) \\
\frac{\partial w_{k}}{\partial t}=\nabla\left(K_{l} \nabla p_{c}\right)+\nabla\left(\frac{\delta_{v} p_{v}}{\rho_{l} R_{v} T} \nabla p_{c}+\frac{\delta_{v} p_{v}}{\rho_{l} R_{v} T^{2}}\left(\rho_{l} L_{v}-p_{c}\right) \nabla T\right)
\end{gathered}
$$

where $\mathrm{c}_{0}, \mathrm{Cl}_{\mathrm{l}}$ and $\mathrm{c}_{\mathrm{v}}$ the specific heat capacity of the material, liquid water $(4180 \mathrm{~J} / \mathrm{kgK})$ and vapour (1880 J/kgK), respectively, $\rho_{0}$ the material density $\left(\mathrm{kg} / \mathrm{m}^{3}\right)$, w the moisture content $\left(\mathrm{kg} / \mathrm{m}^{3}\right), \mathrm{T}$ the temperature $(\mathrm{K}), \mathrm{t}$ the time $(\mathrm{s}), \mathrm{p}_{\mathrm{c}}$ the capillary pressure $(\mathrm{Pa}), \lambda$ the thermal conductivity $(\mathrm{W} / \mathrm{mK}), \mathrm{g}_{1}$ and $\mathrm{g}_{\mathrm{v}}$ the liquid and vapour flow $\left(\mathrm{kg} / \mathrm{m}^{2} \mathrm{~s}\right)$, respectively, $L_{v}$ the heat of vaporisation $\left(3.1310^{6} \mathrm{~J} / \mathrm{kg}\right), \mathrm{K}_{\mathrm{l}}$ the liquid permeability (s), 
Postprint: Vereecken E, Van Gelder L, Janssen H, Roels S, 2015. Interior insulation for wall retrofitting - A probabilistic analysis of energy savings and hygrothermal risks. Energy and Buildings 89: 231-244. doi.org/10.1016/j.enbuild.2014.12.031

$\mathrm{p}_{\mathrm{v}}$ the vapour pressure $(\mathrm{Pa}), \delta_{\mathrm{v}}$ the water vapour permeability $(\mathrm{s}), \rho$ I the density of water $\left(1000 \mathrm{~kg} / \mathrm{m}^{3}\right)$ and $R_{v}$ the gas constant of water $(461.89 \mathrm{~J} / \mathrm{kg} . \mathrm{K})$.

The moisture balance of the room is described by the effective capacitance (EC-) model [46], wherein the air capacity is enlarged by using the hygric inertia of the $\operatorname{room}\left(\mathrm{HIR}^{\star}\right)$ :

$$
\left(\frac{V}{R_{v} T_{i}}+\frac{100 H I R^{*} V}{p_{v, s a t}\left(T_{i}\right)}\right) \cdot \frac{\partial p_{v i}}{\partial t}=\left(p_{v e}-p_{v i}\right) \cdot \frac{n V}{3600 R_{v} T_{i}}+G_{v p}-\beta A\left(p_{v i}-p_{v s}\right)
$$

where $\mathrm{V}$ the room volume $\left(\mathrm{m}^{3}\right)$, $\mathrm{T}_{i}$ the indoor temperature $(\mathrm{K})$, pvi/e the partial vapour pressure of indoor/outdoor air $(\mathrm{Pa}), \mathrm{n}$ the ventilation rate $(1 / \mathrm{h}), \mathrm{G}_{\mathrm{vp}}$ the indoor vapour production $(\mathrm{kg} / \mathrm{s}), \beta$ the moisture transfer coefficient $(\mathrm{s} / \mathrm{m})$, A the surface area $\left(\mathrm{m}^{2}\right)$ and $p_{v s}$ the partial vapour pressure at the surface $(\mathrm{Pa})$. The $H I R^{*}$-value $\left(\mathrm{kg} /\left(\mathrm{m}^{3} . \% \mathrm{RH}\right)\right)$ takes into account moisture exchanging elements such as books, furniture, etc. In the current study, the moisture exchange between the exterior wall and the room is not included in the $\mathrm{HIR}^{\star}$-value, but described by the last term in Eq.(4). No zone heat balance calculation is needed, since the zone temperature is imposed based on the distribution of the indoor temperature given in Table 1. The simulations are started from September $1^{\text {st }}$. To exclude a potential influence of the starting conditions, the first 4 months in these simulations are not taken into account in the probabilistic analysis.

\subsection{Probabilistic assessment}

As already mentioned in section 2, a Monte Carlo design approach is coupled to this hygrothermal model in order to take all insulation systems and uncertain variables into account. Thereto, a simplified version of the probabilistic design methodology of 
Postprint: Vereecken E, Van Gelder L, Janssen H, Roels S, 2015. Interior insulation for wall retrofitting - A probabilistic analysis of energy savings and hygrothermal risks. Energy and Buildings 89: 231-244. doi.org/10.1016/j.enbuild.2014.12.031

Van Gelder et al. [17] is used. This design approach allows quantification of the probabilistic distributions of the considered performances for each of the insulation systems. Therefore, the input parameters are sampled several times according to their probability and the deterministic simulation is repeated for all of these samples. To reduce the required number of samples [48], a maximin Latin Hypercube sampling scheme is used. This is a distance-based space-filling scheme that maximises the minimal distance between Latin Hypercube sampling points [49]. To further improve the calculation efficiency, the deterministic model can be replaced by a faster surrogate model and a sensitivity analysis can be performed, however, this is not done in this paper.

For each of the design options in this paper, the same samples are used in order to reliably compare their output distributions. For that purpose, the convergence of these distributions has to be checked as well. Therefore, a sample of 36 values is created and extra sample sets of this size are added until convergence is reached. This number is chosen because it is a multiple of all considered discrete input levels and, hence, ensures that all values have equal probability. Three sets of 36 samples, thus 108 in total, were needed to obtain convergence for all considered performances and for all insulation systems.

\section{RESULTS}

To discuss the thermal performance of the wall assemblies and the hygrothermal risks, the heat loss and the hygrothermal risk indicators will be given as a function of the dry thermal resistance of the corresponding interior insulation system ( $\left.R_{\text {dry,insul }}\right)$. The results will be shown for the vapour tight XPS system and the capillary active 
Postprint: Vereecken E, Van Gelder L, Janssen H, Roels S, 2015. Interior insulation for wall retrofitting - A probabilistic analysis of energy savings and hygrothermal risks. Energy and Buildings 89: 231-244. doi.org/10.1016/j.enbuild.2014.12.031

calcium silicate insulation system, and this for the three insulation thicknesses. The conclusions found for the interior insulation system comprising a mineral wool layer in combination with a vapour barrier or smart vapour retarder are for the studied winter period similar as those obtained for the XPS system and are hence not shown. As a reference, also the results for the non-insulated wall are presented. The results for each design option will be shown based on box plots. The central mark in these box plots indicates the median, while the $25^{\text {th }}$ and $75^{\text {th }}$ percentile are indicated by the edges of the box plots. Additionally, the most extreme data points not considered as an outlier and the outliers are shown by the whiskers and the circles, respectively.

\subsection{Total heat loss}

The thermal resistance of an insulation system can deviate from its theoretical dry value [11]. Therefore, to indicate the thermal performance of the studied interior insulation systems, Figure 3 shows the total heat loss through the wall in January. As already indicated by the dry thermal conductivity given in Table A.1, a vapour tight system yields a higher dry thermal resistance than a capillary active system of identical thickness. Moreover, the spread in total heat loss found for the walls with a vapour tight system - and thus the real thermal resistance of the insulation system is much smaller than found for the capillary active system and outliers are much more probable for the latter system. This large spread for the capillary active system together with the presence of outliers is due to the potential moisture accumulation in the insulation material. Based on all this, it can be concluded that the vapour tight systems perform most robust in respect to the thermal performance of the wall. 
Postprint: Vereecken E, Van Gelder L, Janssen H, Roels S, 2015. Interior insulation for wall retrofitting - A probabilistic analysis of energy savings and hygrothermal risks. Energy and Buildings 89: 231-244. doi.org/10.1016/j.enbuild.2014.12.031

Note also that the decrease in total heat loss is getting smaller with increasing dry thermal insulation resistance. The total heat loss still decreases, though only slightly, when going from a $14 \mathrm{~cm}$ insulation to a $30 \mathrm{~cm}$ thick insulation system. Hence, when applying interior insulation, an insulation material with a thermal resistance larger than approximately $4 \mathrm{~m}^{2} \mathrm{~K} / \mathrm{W}$ is often not worth it, especially because it involves a reduction in floor area. Furthermore, the probabilistic study shows that the spread in total heat loss decreases as the insulation thickness increases.

Figure 3. Total heat loss in January as a function of the dry thermal resistance of the studied insulation systems.

The characteristics or boundary conditions which provoke these spreads were in a next step determined based on an additional sensitivity analysis with Spearman's rank correlation coefficients [50][51]. In this analysis, the wind-driven rain load was found to have a significant influence on the heat loss through the walls with a capillary active interior insulation system. Additionally, the ease in which moisture is transported toward the warm side of the masonry is expected to influence the heat loss. Two hygric brick characteristics that are of main importance in this moisture transport are the capillary absorption coefficient $A_{c a p}\left(\mathrm{~kg} /\left(\mathrm{m}^{2} \mathrm{~s}\right)\right)$ and the capillary moisture content $\mathrm{w}_{\text {cap }}\left(\mathrm{kg} / \mathrm{m}^{2}\right)$. A large capillary absorption coefficient facilitates the moisture uptake in the brick layer. The larger the capillary moisture content, the more moisture can be stored in the brick. Hence, the ratio of both characteristics ( $\left.A_{c a p} / w_{c a p}\right)$ influences the inward movement of the moisture front (cfr. the water penetration 
Postprint: Vereecken E, Van Gelder L, Janssen H, Roels S, 2015. Interior insulation for wall retrofitting - A probabilistic analysis of energy savings and hygrothermal risks. Energy and Buildings 89: 231-244. doi.org/10.1016/j.enbuild.2014.12.031

coefficient). In addition, the time needed by the moisture to reach the warm side of the masonry wall depends on the masonry thickness dbrick $(\mathrm{m})$. Therefore, the influence of the masonry characteristics is analysed based on a combined parameter: $A_{c a p} /\left(w_{c a p} \times d_{b r i c k}\right)$, which is in what follows indicated as the moisture penetration factor. A high moisture penetration factor stands for a larger risk for the moisture to reach the warm side of the masonry.

The influence of both the yearly rain load and the moisture penetration factor on the heat loss is shown in Figure 4. In this figure, the results for the reference noninsulated wall, the walls with a $14 \mathrm{~cm}$ insulation and the wall with a $2 \mathrm{~cm}$ calcium silicate are plotted. For the non-insulated wall, a positive regression is found between the rain load and the total heat loss; though the correlation is rather small (indicated by the thinner regression line). For the capillary active system, a better correlation can be observed, while for the vapour tight insulation system the influence of the rain load is negligible. While the moisture can be accumulated in the capillary active insulation system, this is not the case for the vapour tight systems. Also between the moisture penetration factor and the total heat loss a positive regression is found; though this is less pronounced for the insulated walls. Indeed, since the masonry wall is exposed to alternating wetting and drying periods, also the moisture storage capacity and the moisture dependent liquid permeability are expected to have an influence on the risk of the moisture reaching the insulation system. For a thinner capillary insulation system, the correlation between the moisture penetration factor and the total heat loss seems to be larger than for the $14 \mathrm{~cm}$ thick insulation systems, as shown in Figure 4d. Though, keep in mind that in this case the thermal resistance of the masonry wall (which is proportional to $d_{\text {brick}}$ ) will have a larger share in the total 
Postprint: Vereecken E, Van Gelder L, Janssen H, Roels S, 2015. Interior insulation for wall retrofitting - A probabilistic analysis of energy savings and hygrothermal risks. Energy and Buildings 89: 231-244. doi.org/10.1016/j.enbuild.2014.12.031

thermal resistance of the wall assembly. The larger correlation between the moisture penetration factor and the total heat loss for the non-insulated wall (Figure 4a) is obvious since the thermal resistance of this wall assembly is solely obtained by the masonry wall.

Based on all this, it can be concluded that - in respect to the heat loss - a capillary active insulation is more sensitive to wind-driven rain. This phenomenon is, furthermore, independent of the brick characteristics; also if the characteristics of the brick are not beneficial for a fast moistening of the outer wall leaf a high rain load could result in an extra heat loss. Thus, the thermal resistance of a capillary active insulation system can only be fully exploited on walls with a low wind-driven rain load.

Figure 4. Total heat loss in January as a function of the yearly wind-driven rain load and the moisture penetration factor: a) non-insulated reference wall, b) wall with a $14 \mathrm{~cm}$ capillary active system, c) wall with a $14 \mathrm{~cm}$ XPS system, d) wall with a $2 \mathrm{~cm}$ capillary active system. The gray points are the projections of the black points. The red lines indicate the correlations between the rain and the total heat loss and between the moisture penetration factor and the total heat loss (based on the projected points).

\subsection{Frost damage}

Figure 5 shows the maximal number of moist frost-thaw cycles. By applying a vapour tight interior insulation system a larger number of moist frost-thaw cycles than found for the non-insulated wall might be induced, especially for larger insulation 
Postprint: Vereecken E, Van Gelder L, Janssen H, Roels S, 2015. Interior insulation for wall retrofitting - A probabilistic analysis of energy savings and hygrothermal risks. Energy and Buildings 89: 231-244. doi.org/10.1016/j.enbuild.2014.12.031

thicknesses. This increase is less pronounced for the capillary active interior insulation system. Note however that, especially for the walls with a $2 \mathrm{~cm}$ thick insulation layer (Rdry,insul $=0.33$ and $0.61 \mathrm{~m}^{2} \mathrm{~K} / \mathrm{W}$ for the XPS system and the capillary active system, respectively), in most cases no moist frost-thaw cycles are detected.

In addition to the number of frost-thaw cycles also the duration below subfreezing temperatures while the critical moisture content is exceeded is of importance. Based on this duration (not shown) the vapour tight system emerges as the most risky insulation technique in respect to frost damage as well.

Figure 5. Maximal number of moist frost-thaw cycles ( $\left.w>0.25 w_{\text {sat }}\right)$ as a function of the dry thermal resistance of the studied insulation systems (freezing point $=-2^{\circ} \mathrm{C}$ ).

The influence of the rain load and the moisture penetration factor on the number of moist frost-thaw cycles is visualised in Figure 6. Whereas the graph for the walls with a capillary active system shows a similar behaviour as observed for the non-insulated walls, this is not the case for the walls with a vapour tight system. For the latter insulation system, a high rain load can result in a much larger number of moist frostthaw cycles. In addition, a negative regression between the number of moist frostthaw cycles and the moisture penetration factor is detected. The lower the latter parameter, especially if caused by a low value for $A_{c a p} / w_{c a p}$, the less easily moisture is transported inward. Hence, more moisture is stored near the outer surface, which could induce more moist cycles. The coefficient of determination is, however, too small to draw definite conclusions. 
Postprint: Vereecken E, Van Gelder L, Janssen H, Roels S, 2015. Interior insulation for wall retrofitting - A probabilistic analysis of energy savings and hygrothermal risks. Energy and Buildings 89: 231-244. doi.org/10.1016/j.enbuild.2014.12.031

Figure 6. Number of moist frost-thaw cycles per year as a function of the yearly rain load and the moisture penetration factor: a) non-insulated reference wall, b) wall with a $14 \mathrm{~cm}$ capillary active system, c) wall with a $14 \mathrm{~cm}$ XPS system. The gray points are the projections of the black points. The red lines indicate the correlations between the rain and the number of moist frost-thaw cycles and between the moisture penetration factor and the number of moist frostthaw cycles (based on the projected points).

\subsection{Moisture level in the construction}

To obtain a view on the moisture level in the masonry wall, (1) the number of hours that the relative humidity between the masonry wall and the insulation system exceeds $99.9 \%$ and (2) the number of hours that the relative humidity at $5 \mathrm{~cm}$ of the insulation system exceeds $95 \%$ is studied. Figure 7 shows for January the number of hours that the relative humidity between the masonry wall and the insulation system exceeds $99.9 \%$. As a reference, the number of hours that the relative humidity between the non-insulated masonry and the interior plaster layer exceeds $99.9 \%$ is plotted. The addition of the XPS systems induces an increase of the number of hours. Note however that for a number of cases also for the non-insulated wall a high number of hours can already be observed because of a high wind-driven rain load. When applying a calcium silicate layer, in general, the number of hours is lower than found for the XPS systems, since an inward moisture redistribution and drying out remains possible. Despite of the vapour open character of a capillary active system, the capillary active system performs, in general, better in respect to the relative humidity at the warm side of the masonry. 
Postprint: Vereecken E, Van Gelder L, Janssen H, Roels S, 2015. Interior insulation for wall retrofitting - A probabilistic analysis of energy savings and hygrothermal risks. Energy and Buildings 89: 231-244. doi.org/10.1016/j.enbuild.2014.12.031

Figure 7. Number of hours in January that the relative humidity between the masonry wall and the insulation system exceeds $99.9 \%$ as a function of the dry thermal resistance of the studied insulation systems. For the non-insulated wall, the number of hours that the relative humidity between the masonry wall and the plaster layer exceeds $99.9 \%$ is plotted.

The influence of the rain load and the moisture penetration factor on the relative humidity at the warm side of the masonry wall is shown in Figure 8 . The rain load is found to have an important influence on the results obtained for the non-insulated wall. A positive regression can be observed. This is even more pronounced for the wall with the vapour tight XPS system, since an inward drying is not possible. For the capillary active system, the correlation is less, due to the inward moisture redistribution. The impact of the moisture penetration factor is for the different wall assemblies less clear. In general, one would expect a positive correlation. Though, for instance, the liquid permeability of the brick which determines the drying behaviour or other stochastic input parameters that have a significant influence might explain the somewhat strange regression lines. Regarding the stochastic input parameters, based on the Spearman's rank correlation coefficients the orientation was found to be a significant input parameter as well.

The number of hours that the relative humidity in the brick at $5 \mathrm{~cm}$ from the interior insulation system (or plaster layer for the non-insulated wall) exceeds $95 \%$ is shown in Figure 9, and this as an indicator for a potential wood decay of wooden beam ends. For all of the options, a relative humidity higher than $95 \%$ during the whole month (= 744 hours) is possible. The median is found to increase after applying an interior insulation system, and this especially for the XPS system. Hence, a vapour 
Postprint: Vereecken E, Van Gelder L, Janssen H, Roels S, 2015. Interior insulation for wall retrofitting - A probabilistic analysis of energy savings and hygrothermal risks. Energy and Buildings 89: 231-244. doi.org/10.1016/j.enbuild.2014.12.031

tight system is the most risky technique when wooden beam ends are present. In addition, a larger insulation thickness is shown to result in a higher risk.

Figure 8. Number of hours in January that the relative humidity between the masonry wall and the insulation system (or plaster for the non-insulated reference wall) exceeds $99.9 \%$ as a function of the yearly rain load and the moisture penetration factor: a) non-insulated reference wall, b) wall with a $14 \mathrm{~cm}$ capillary active system, c) wall with a $14 \mathrm{~cm}$ vapour tight system. The gray points are the projections of the black points. The red lines indicate the correlations between the rain and the exceeding hours and between the moisture penetration factor and the exceeding hours (based on the projected points).

Figure 9. Number of hours in January that the relative humidity in the masonry wall (at $5 \mathrm{~cm}$ from the interior insulation system) exceeds $95 \%$ as a function of the dry thermal resistance of the studied insulation systems.

The rain load is found to have an important influence on the relative humidity in the masonry wall, as shown in Figure 10. A positive regression can be observed. Note however that a large number of hours with a relative humidity higher than $95 \%$ might occur for a rather limited rain load as well. Idem as found for the number hours that the relative humidity between the masonry wall and the insulation system (or plaster layer) exceeds $99.9 \%$, the correlation with the moisture penetration factor is, however, less clear. 
Postprint: Vereecken E, Van Gelder L, Janssen H, Roels S, 2015. Interior insulation for wall retrofitting - A probabilistic analysis of energy savings and hygrothermal risks. Energy and Buildings 89: 231-244. doi.org/10.1016/j.enbuild.2014.12.031

Figure 10. Number of hours in January that the relative humidity in the masonry wall (at $5 \mathrm{~cm}$ from the interior insulation system) exceeds $95 \%$ as a function of the yearly rain load and the moisture penetration factor: a) non-insulated reference wall, b) wall with a $14 \mathrm{~cm}$ capillary active system, c) wall with a $14 \mathrm{~cm}$ XPS system. The gray points are the projections of the black points. The red lines indicate the correlations between the rain and the exceeding hours and between the moisture penetration factor and the exceeding hours (based on the projected points).

The influence of applying an interior insulation system on the moisture content in the masonry wall is clearly visible in the moisture profiles shown in Figure 11 as well. Each plot shows three moisture profiles: the yearly averaged moisture content, the annual maximum moisture content and the moisture content at January $5^{\text {th }} 8: 00 \mathrm{AM}$, and this in function of the position in the wall. For the plotted case, adding a vapour tight XPS system generally results in an increased moisture content over the complete depth of the masonry wall. The moisture profiles in a wall assembly with a capillary active system are, however, more in line with those found for the noninsulated wall, showing a minor impact on the moisture response. Only a slightly higher moisture content near the exterior surface can be observed for the wall with a capillary active system, which explains the lower number of moist frost-thaw cycles shown in the previous section. Near the capillary active insulation system, the maximum moisture content is much lower since the moisture is transported inward via the capillary active insulation system. 
Postprint: Vereecken E, Van Gelder L, Janssen H, Roels S, 2015. Interior insulation for wall retrofitting - A probabilistic analysis of energy savings and hygrothermal risks. Energy and Buildings 89: 231-244. doi.org/10.1016/j.enbuild.2014.12.031

Figure 11. Moisture profiles for one of the runs: a) non-insulated masonry wall, b) vapour tight XPS-system, c) capillary active calcium silicate system. 1 = masonry wall, 2 = XPS, 3 = gypsum board, $\mathbf{4}$ = glue mortar, $\mathbf{5}=$ calcium silicate, $\mathbf{6}=$ plaster .

\subsection{Relative humidity on the indoor surface}

Figure 12 shows the number of hours that the relative humidity on the indoor surface exceeds $80 \%$ as a function of the dry thermal resistance of the different insulation systems, and this for January. For the walls with a vapour tight interior insulation system, the indoor surface relative humidity does not reach $80 \%$. Due to the high vapour resistance and the low liquid permeability of the vapour tight insulation system, the moisture stored in the masonry wall cannot be transported toward the indoor surface. On the other hand, when applying calcium silicate insulation, moisture in the wall structure can be transported inward which can for some of the studied boundary conditions result in an exceedance of the lower limit of relative humidity for mould growth. The insulation thickness seems to have an influence on this behaviour. In general, the smaller the insulation thickness, the larger the indoor surface relative humidity. Remark however that in the current study, also for the noninsulated wall the lower limit for mould growth could be exceeded. The boundary conditions in most of the runs resulting in a too high indoor surface relative humidity when applying a calcium silicate insulation system induced already for the noninsulated wall a high indoor surface relative humidity. Though, a higher indoor surface relative humidity or a larger period exposed to a high indoor surface relative humidity after applying a calcium silicate interior insulation system is not impossible. A similar - though less pronounced - trend is found for the indoor relative humidity. 
Figure 12. Number of hours in January that the relative humidity on the indoor surface exceeds $80 \%$ as a function of the dry thermal resistance of the studied insulation systems.

The influence of the rain load and the moisture penetration factor on the number of hours that the indoor surface relative humidity exceeds $80 \%$ is shown in Figure 13 . While the rain load seems to have a large impact for the non-insulated wall and the wall with the capillary active insulation system, when applying the vapour tight XPS system this behaviour is not found. In respect to the moisture penetration factor, the correlation is not significant. Apparently, to diminish the risk on a too high indoor surface relative humidity when applying a capillary active interior insulation system the rain load should be limited. A high rain load might, even if the properties of the masonry wall are not beneficial for an easy moisture transport toward the warm side of the masonry wall (small $A_{c a p}$, large $w_{c a p}$, large dbrick), result in a large number of exceeding hours.

Figure 13. Number of hours in January that the relative humidity on the indoor surface exceeds $80 \%$ as a function of the yearly rain load and the moisture penetration factor: a) non-insulated reference wall, b) wall with a $14 \mathrm{~cm}$ capillary active system, c) wall with a $14 \mathrm{~cm}$ XPS system. The gray points are the projections of the black points. The red lines indicate the correlations 
Postprint: Vereecken E, Van Gelder L, Janssen H, Roels S, 2015. Interior insulation for wall retrofitting - A probabilistic analysis of energy savings and hygrothermal risks. Energy and Buildings 89: 231-244. doi.org/10.1016/j.enbuild.2014.12.031

between the rain and the exceeding hours and between the moisture penetration factor and the exceeding hours (based on the projected points).

\section{Discussion}

Based on the probabilistic approach applied in the current study some conclusions on the applicability of interior insulation systems can be made. Though, some remarks should be considered. First of all, it should be noted that a realistic input in a probabilistic study is of major importance, as the output is always the result of this input. Hence, caution is required when using the obtained results while dealing with other boundary conditions (e.g. other climates, cracks in the masonry wall, etc.). Based on the probabilistic study, trends can be defined and hence the results can serve as a decision tool. However, in the end, a building owner is mainly interested in his or her own case. Consequently, for excessive boundary conditions or when based on the probabilistic decision tool no clear advice can be achieved, an extra case-specific study might be recommended. Additionally, the probabilistic study on the hygrothermal performance of interior insulation systems as applied in the current study contains some simplifications or assumptions. For instance, the interior insulation systems are assumed to be applied properly and thus potential air rotations resulting in an enlarged risk on condensation, an incorrect working of the capillary active system or extra heat losses are excluded. As an interior finishing layer, a rather vapour open layer is applied. The modification of this layer by for instance adding a more vapour tight painting coat could negatively influence the results for the capillary active insulation system, as shown in [11]. Furthermore, in the current study solely the most commonly known capillary active insulation system is 
Postprint: Vereecken E, Van Gelder L, Janssen H, Roels S, 2015. Interior insulation for wall retrofitting - A probabilistic analysis of energy savings and hygrothermal risks. Energy and Buildings 89: 231-244. doi.org/10.1016/j.enbuild.2014.12.031

analysed, and this with one type of glue mortar. In practice, other capillary active interior insulation systems are on the market. A difference in moisture permeability will influence the moisture distribution in the system. The glue mortar might influence the hygrothermal performance of the system, as indicated in [34]. To end, it should be noted that, for a capillary active as well as for a vapour tight interior insulation system, a rain shelter could avoid some damage patterns caused by a high rain load. Provision of a rain shelter for the wall does, however, nullify the main motivation for capillary active insulation, which is that they allow an inward drying of the absorbed wind-driven rain. Moreover, if the wall is not exposed to rain, there is no reason to choose for a capillary active system, as its thermal performance is less while the hygrothermal risks are similar to those found for a vapour tight system. On the other hand, for walls with a low wind-driven rain load, capillary active systems could be beneficial since the hygric performance of the masonry wall is in closer agreement to this of the non-insulated wall.

\section{Conclusion}

In the current paper a probabilistic approach is used to analyse the energy savings and the hygrothermal risks caused by different interior insulation systems. An overview of the obtained results is given in Table 4. Vapour tight interior insulation systems were found to perform best in respect to the potential energy savings. Yet, the additional energy savings achieved by increasing the insulation thickness decrease, and this for the different insulation systems. In this respect, the heat loss reduction should be weighed up against the floor area reduction. On the other hand, the larger thermal and vapour resistance of the vapour tight systems results in a larger risk on frost damage. Additionally, an elevated moisture retention in the 
Postprint: Vereecken E, Van Gelder L, Janssen H, Roels S, 2015. Interior insulation for wall retrofitting - A probabilistic analysis of energy savings and hygrothermal risks. Energy and Buildings 89: 231-244. doi.org/10.1016/j.enbuild.2014.12.031

masonry wall might induce damage on wooden beams ends or other wooden structures. Similar conclusions were found for the interior insulation system comprising a mineral wool layer in combination with a smart vapour retarder, even though this system is in the literature promoted as a novel system that aims an inward drying of the wall. It should however be noted that the current work is limited to a comparison of the hygrothermal performance during the heating season. A different behaviour might occur during the cooling season. A more extended discussion of the smart vapour retarder can be found in [35].

A capillary active interior insulation system results in a smaller thermal improvement. The heat loss during the heating season will be higher than found for a vapour tight system. The thermal performance of the capillary active insulation system is furthermore more sensitive to a moisture load induced by for instance wind-driven rain. This moisture could also be redistributed inward and hence might increase the indoor surface relative humidity. The risk on a too high indoor surface relative humidity is, however, mainly present if a high indoor surface relative humidity can already be observed for the non-insulated wall. On the other hand, due to the inward moisture redistribution less moisture is accumulated in the masonry wall, which is beneficial to restrain potential moisture related failure in de masonry wall and eventually in wooden structures.

Based on the outcomes mentioned above, some recommendations on interior insulation systems can be formulated. In general, for buildings without wooden beam ends and with a facade not sensitive to frost damage a vapour tight insulation system is favourable. If frost damage should absolutely be avoided, calcium silicate might be a better solution. Also when wooden beam ends are present, calcium silicate is 
Postprint: Vereecken E, Van Gelder L, Janssen H, Roels S, 2015. Interior insulation for wall retrofitting - A probabilistic analysis of energy savings and hygrothermal risks. Energy and Buildings 89: 231-244. doi.org/10.1016/j.enbuild.2014.12.031

preferable above a vapour tight system. Though, a more in depth study of interior insulation in combination with wooden beam ends remains indispensable.

Table 4. Overview of the energy savings and the hygrothermal performance for the studied cases. For each performance criterion, the results that make one of both interior insulation systems less favourable than the other are indicated in red.

\section{ACKNOWLEDGEMENTS}

The results within this paper have been partially obtained within the IWT VIS-Traject 'Renofase' (IWT 120784) funded by the Flemish Government and KUL OT/09/23 'Toward a reliable application of interior insulation for the retrofit of existing buildings' funded by KU Leuven. These financial supports are gratefully acknowledged.

\section{Appendix A}

The hygrothermal properties of the insulation systems and the interior finishing layers are listed in Table A.1. The moisture retention curve and the liquid permeability of these materials are drawn in Figure A.1. The $\mu \mathrm{d}$-values of the vapour barrier and the smart vapour retarder are shown in Figure A.2.

Table A.1. Material properties insulation systems and interior finishing layers.

Figure A.1. a) Moisture retention curve and b) liquid permeability of the insulation systems and the finishing layers.

Figure A.2. $\mu \mathrm{d}$-value for a) polyethylene vapour barrier, b) smart vapour retarder. 


\section{REFERENCES}

[1] Mure II, 2013. Mure II - Database on energy efficiency policies and measures. www.measures-odyssee-mure.eu/ (accessed 2 June 2014).

[2] IEA, 2014. http://www.iea.org/aboutus/faqs/energyefficiency/ (accessed 14 August 2014)

[3] A. Uihlein, P. Eder, Towards additional policies to improve the environmental performance of buildings. European Commission, JRC-IPTS, EUR 23775 EN, Office for Official Publications of the European Communities, Luxembourg, 2009.

[4] P. Häupl, K. Jurk, H. Petzold, Inside thermal insulation for historical facades, in: Research in Building Physics, eds. Carmeliet, Hens, Vermeir; Lisse: A.A. Balkema Publishers, 2003, pp. 463-469.

[5] J. Grunewald, U. Ruisinger, P. Häupl, The Rijksmuseum Amsterdam hygrothermal analysis and dimensioning of thermal insulation. Research in Building Physics and Building Engineering, eds. Fazio, Ge, Rao, Desmarais, Taylor \& Francis group, London, 2006, pp. 345-352.

[6] E. Vereecken, S. Roels, A comparison of the hygric performance of interior insulation systems: a hot box-cold box experiment, Energy and Buildings 80 (2014) 37-44.

[7] J. Straube, C. Schumacher, Interior insulation retrofits of load-bearing masonry walls in cold climates, Building Science Digest 114, 2007.

[8] Z. Pavlik, R. Cerny, Hygrothermal performance study of an innovative interior thermal insulation system, Applied Thermal Engineering 29 (2010) 1941-1946.

[9] Remmers IQ-Therm - The intelligent interior insulation - The unique capillary thermal insulation.

http://www.remmers.co.uk/fileadmin/user_upload/brochures/interior_insulation/79 6_-_iq-therm/796_GB_iQ-Therm.pdf (accessed 2 June 2014).

[10] EP 1900884 A1. 2008. Europäische petentanmeldung, Holzweichfaserplatte für die raumseitige Dämmung, 19.03.2008 Patentblatt 2008/12.

[11] E. Vereecken, S. Roels, Capillary active interior insulation: Do the advantages really offset potential disadvantages?, Materials and Structures (2014), doi: 10.1617/s11527-014-0373-9.

[12] I.A. Macdonald, P. Strachan, Practical application of uncertainty analysis, Energy and Buildings 33(3) (2001) 219-227.

[13] M.S. De Wit, G. Augenbroe, Analysis of uncertainty in building design evaluations and its implications, Energy and Buildings 34(9) (2002) 951-958.

[14] J. Haarhoff, E. Mathews, A Monte Carlo method for thermal building simulation. Energy and Buildings 38(12) (2006) 1395-1399. 
Postprint: Vereecken E, Van Gelder L, Janssen H, Roels S, 2015. Interior insulation for wall retrofitting - A probabilistic analysis of energy savings and hygrothermal risks. Energy and Buildings 89: 231-244. doi.org/10.1016/j.enbuild.2014.12.031

[15] V. Corrado, H.E. Mechri, Uncertainty and Sensitivity Analysis for Building Energy Rating, Journal of Building Physics 33(2) (2009) 125-156.

[16] A.S. Silva, E. Ghisi, Uncertainty Analysis of User Behaviour and Physical Parameters in Residential Building Performance Simulation, Energy and Buildings (2014), http://dx.doi.org/10.1016/j.enbuild.2014.03.001

[17] L. Van Gelder, H. Janssen, S. Roels, Probabilistic design and analysis of building performances: methodology and application example, Energy and Buildings 79 (2014) 202-211.

[18] A. Soroudi, T. Amraee, Decision making under uncertainty in energy systems : State of the art, Renewable and Sustainable Energy Reviews 28 (2013) 376-384.

[19] A.M. Rysanek, R. Choudhary, Optimum building energy retrofits under technical and economic uncertainty, Energy and Buildings 57 (2013) 324-337.

[20] A.T. Booth, R. Choudhary, Decision making under uncertainty in the retrofit analysis of the UK housing stock: Implications for the Green Deal, Energy and Buildings 64 (2013) 292-308.

[21] C.J. Hopfe, G.A. Augenbroe, J.L.M. Hensen, Multi-Criteria Decision Making Under Uncertainty In Building Performance Assessment, Building and Environment 69 (2013) 81-90.

[22] L. Van Gelder, H. Janssen, S. Roels, Retrofitting cavity walls - probabilistic study of energy savings and moisture risks. In 5th International Building Physics Conference. Kyoto, Japan, 2012.

[23] Z. Sadovsky, Koronthalyova O, Matiasovsky P, Mikulova K, Probabilistic modelling of mould growth in buildings, Journal of Building Physics 37 (2014) 348-366.

[24] E. Vereecken, S. Roels, Hygric performance of a massive masonry wall: How do the mortar joints influence the moisture flux?, Construction and Building Materials 41 (2013) 697-707.

[25] A.H.P. Maurenbrecher, C.J. Shirtliffe, M.Z. Rousseau, M.N.A. Saïd, Monitoring the hygrothermal performance of a masonry wall with and without thermal insulation. Proceedings of the $8^{\text {th }}$ Canadian Masonry Symposium held in Jasper, Alberta, 1998.

[26] G. Fagerlund, Degré critique de saturation. Un outil pour l'estimation de la résistance au gel des matériaux de construction, Matériaux et Construction 23(4) (1971) 271-285.

[27] P. Mensinga, J. Straube, C. Schumacher, Assessing the freeze-thaw resistance of clay brick for interior insulation retrofit projects. Thermal Performance of Exterior Envelopes of Whole Buildings XI International Conference, December 5-9, Clearwater, Florida, 2010.

[28] S. Gnoth, K. Jurk, P. Strangfeld, Hygrothermisches Verhalten eingebetteter Holzbalkenköpfe in innengedämmten Außen mauerwerk. Bauphysik 27(2) (2005). 
Postprint: Vereecken E, Van Gelder L, Janssen H, Roels S, 2015. Interior insulation for wall retrofitting - A probabilistic analysis of energy savings and hygrothermal risks. Energy and Buildings 89: 231-244. doi.org/10.1016/j.enbuild.2014.12.031

[29] H. Stopp, P. Strangfeld, Hygrothermics of wooden beam end in envelope parts of buildings, in: Research in Building Physics and Building Engineering, eds. Fazio, Ge, Rao, Desmarais, Taylor \& Francis group, London, pp. 259-267, 2006

[30] M. Morelli, S. Svendsen, Investigation of interior post-insulated masonry walls with wooden beam ends, Journal of Building Physics 36(3) (2013) 256-293.

[31] H. Viitanen, T. Toratti, L. Makkonen, S. Thelandersson, T. Isaksson, E. Früwald, J. Jermer, F. Englund, E. Suttie, Modelling of service life and durability of wooden structures. In Proceedings $9^{\text {th }}$ Nordic Symposium on Building Physics NSB 2011, 29 May - 2 June 2011.

[32] K. Sedlbauer, Prediction of mould growth by hygrothermal calculation, Journal of Thermal Envelope and Building Science 25(4) (2002) 321-336.

[33] E. Vereecken, S. Roels, Review of mould prediction models and their influence on mould risk evaluation, Building and Environment 51 (2012) 296-310.

[34] G. Scheffler, J. Grunewald, Material development and optimisation supported by numerical simulation for a capillary-active inside insulation material, in: Research in Building Physics, eds. Carmeliet, Hens, Vermeir. Lisse: A.A. Balkema Publishers, pp. 463-469, 2003.

[35] E. Vereecken, Hygrothermal analysis of interior insulation for renovation projects, PhD Thesis, KU Leuven, Belgium, 2013.

[36] E. Vereecken, S. Roels, A numerical study of the influence of the hydraulic interface contact on the hygric performance of multi-layered systems, In Proceedings XIII International Conference on Durability of Building Materials and Components. XIII DBMC, São Paulo, 2-5 September, 2014.

[37] H. Künzel, Flexible vapour control solves moisture problems of building assemblies - Smart retarder to replace the conventional PE-film, Journal of Building Physics 23 (1999) 95-102.

[38] K. Blümel, Entwicklung von Testreferenzjahren (TRY) für Klimaregionen der Bundesrepublik Deutschland. Techical report. BMFT-Bericht FB-T 86-051, 1986.

[39] A. Nicolai, J. Grunewald, H. Fechner, DELPHIN: Simulation program for coupled heat, air, moisture, salt and VOC transport, 2010. www.bauklimatikdresden.de/delphin (accessed 14 May 2014).

[40] B. Blocken, J. Carmeliet, The influence of the wind-blocking effect by a building on its wind-driven rain exposure, Journal of Wind Engineering and Industrial Aerodynamics 94 (2006) 101-127.

[41] T. Defraeye, B. Blocken, J. Carmeliet, Convective heat transfer coefficients for exterior building surfaces: Existing correlations and CFD modelling, Energy Conversion and Management 52(1) (2011) 512-522.

[42] H. Derluyn, H. Janssen, P. Moonen, J. Carmeliet, Moisture transfer across the interface between brick and mortar joint. In: Proceedings of the $8^{\text {th }}$ Nordic Symposium on Building Physics, p. 865-872, 2008. 
Postprint: Vereecken E, Van Gelder L, Janssen H, Roels S, 2015. Interior insulation for wall retrofitting - A probabilistic analysis of energy savings and hygrothermal risks. Energy and Buildings 89: 231-244. doi.org/10.1016/j.enbuild.2014.12.031

[43] R. Hendrickx, Using the Karsten tube to estimate water transport parameters of porous building materials. The possibilities of analytical and numerical solutions, Materials and Structures 46 (2013) 1309-1320.

[44] C-E. Hagentoft, A. Kalagasidis, B. Adl-Zarrabi, S. Roels, J. Carmeliet, H. Hens, J. Grunewald, M. Funk, R. Becher, D. Shamir, O. Adan, H. Brocken, K. Kumaran, R. Djebbar, Assessment method for numerical prediction models for combined heat, air and Moisture transfer in building components: Benchmarks for oe-dimensional cases, Journal of Thermal Envelope and Building Science 27(4) (2003) 327-352.

[45] NBN D 50-001, 2009. Ventilatievoorzieningen in woongebouwen, in Dutch.

[46] H. Janssen, S. Roels, Qualitative and quantitative assessment of interior moisture buffering by enclosures, Energy and Buildings 41(4) (2009) 382-394.

[47] H. Janssen, B. Blocken, C. Carmeliet, Conservative modelling of the moisture and heat transfer in building components under atmospheric excitation, International Journal of Heat and Mass Transfer 50 (2007) 1128-1140.

[48] $\quad H$. Janssen, Monte-Carlo based uncertainty analysis: Sampling efficiency and sampling convergence, Reliability Engineering \& System Safety 109 (2013) 123132.

[49] R. Jin, W. Chen, A. Sudjianto, An efficient algorithm for constructing optimal design of computer experiments, Journal of Statistical Planning and Inference 134(1) (2005) 268-287.

[50] D. Hamby, A review of techniques for parameter sensitivity analysis of environmental models, Environmental Monitoring and Assessment 32 (1994) 135154.

[51] P. Das, C. Shrubsole, B. Jones, I. Hamilton, Z. Chalabi, M. Davies, A. Mavrogianni, J. Taylor, Using probabilistic sampling-based sensitivity analyses for indoor air quality modelling, Building and Environment 78 (2014) 171-182.

\section{FIGURE CAPTIONS}

Figure 1. Wall composition with hazardous planes indicated.

Figure 2. a) Moisture retention curve and b) liquid permeability of the three brick types.

Figure 3. Total heat loss in January as a function of the dry thermal resistance of the studied insulation systems. 
Postprint: Vereecken E, Van Gelder L, Janssen H, Roels S, 2015. Interior insulation for wall retrofitting - A probabilistic analysis of energy savings and hygrothermal risks. Energy and Buildings 89: 231-244. doi.org/10.1016/j.enbuild.2014.12.031

Figure 4. Total heat loss in January as a function of the yearly wind-driven rain load and the moisture penetration factor: a) non-insulated reference wall, b) wall with a $14 \mathrm{~cm}$ capillary active system, c) wall with a $14 \mathrm{~cm}$ XPS system, d) wall with a $2 \mathrm{~cm}$ capillary active system. The gray points are the projections of the black points. The red lines indicate the correlations between the rain and the total heat loss and between the moisture penetration factor and the total heat loss (based on the projected points).

Figure 5. Maximal number of moist frost-thaw cycles ( $w>0.25 w_{\text {sat }}$ ) as a function of the dry thermal resistance of the studied insulation systems (freezing point $=-2{ }^{\circ} \mathrm{C}$ ).

Figure 6. Number of moist frost-thaw cycles per year as a function of the yearly rain load and the moisture penetration factor: a) non-insulated reference wall, b) wall with a $14 \mathrm{~cm}$ capillary active system, c) wall with a $14 \mathrm{~cm}$ XPS system. The gray points are the projections of the black points. The red lines indicate the correlations between the rain and the number of moist frost-thaw cycles and between the moisture penetration factor and the number of moist frostthaw cycles (based on the projected points).

Figure 7. Number of hours in January that the relative humidity between the masonry wall and the insulation system exceeds $99.9 \%$ as a function of the dry thermal resistance of the studied insulation systems. For the non-insulated wall, the number of hours that the relative humidity between the masonry wall and the plaster layer exceeds $99.9 \%$ is plotted.

Figure 8. Number of hours in January that the relative humidity between the masonry wall and the insulation system (or plaster for the non-insulated reference wall) exceeds $99.9 \%$ as a function of the yearly rain load and the moisture penetration factor: a) non-insulated reference wall, b) wall with a $14 \mathrm{~cm}$ capillary active system, c) wall with a $14 \mathrm{~cm}$ vapour tight system. The gray points are the projections of the black points. The red lines indicate the correlations between the rain and the total heat loss and between the moisture penetration factor and the total heat loss (based on the projected points). 
Postprint: Vereecken E, Van Gelder L, Janssen H, Roels S, 2015. Interior insulation for wall retrofitting - A probabilistic analysis of energy savings and hygrothermal risks. Energy and Buildings 89: 231-244. doi.org/10.1016/j.enbuild.2014.12.031

Figure 9. Number of hours in January that the relative humidity in the masonry wall (at $5 \mathrm{~cm}$ from the interior insulation system) exceeds $95 \%$ as a function of the dry thermal resistance of the studied insulation systems.

Figure 10. Number of hours in January that the relative humidity in the masonry wall (at $5 \mathrm{~cm}$ from the interior insulation system) exceeds $95 \%$ as a function of the yearly rain load and the moisture penetration factor: a) non-insulated reference wall, b) wall with a $14 \mathrm{~cm}$ capillary active system, c) wall with a $14 \mathrm{~cm}$ XPS system. The gray points are the projections of the black points. The red lines indicate the correlations between the rain and the exceeding hours and between the moisture penetration factor and the exceeding hours (based on the projected points).

Figure 11. Moisture profiles for one of the runs: a) non-insulated masonry wall, b) vapour tight XPS-system, c) capillary active calcium silicate system. 1 = masonry wall, $2=X P S, 3=$ gypsum board, 4 = glue mortar, 5 = calcium silicate, $\mathbf{6}=$ plaster .

Figure 12. Number of hours in January that the relative humidity on the indoor surface exceeds $80 \%$ as a function of the dry thermal resistance of the studied insulation systems.

Figure 13. Number of hours in January that the relative humidity on the indoor surface exceeds $80 \%$ as a function of the yearly rain load and the moisture penetration factor: a) non-insulated reference wall, b) wall with a $14 \mathrm{~cm}$ capillary active system, c) wall with a $14 \mathrm{~cm}$ XPS system. The gray points are the projections of the black points. The red lines indicate the correlations between the rain and the exceeding hours and between the moisture penetration factor and the exceeding hours (based on the projected points).

Figure A.1. a) Moisture retention curve and b) liquid permeability of the insulation systems and the finishing layers.

Figure A.2. $\mu d$-value for a) polyethylene vapour barrier, b) smart vapour retarder. 
Postprint: Vereecken E, Van Gelder L, Janssen H, Roels S, 2015. Interior insulation for wall retrofitting - A probabilistic analysis of energy savings and hygrothermal risks. Energy and Buildings 89: 231-244. doi.org/10.1016/j.enbuild.2014.12.031

\section{FIGURES}

Figure 1
(1)
(2) (3)
(4)
(5)
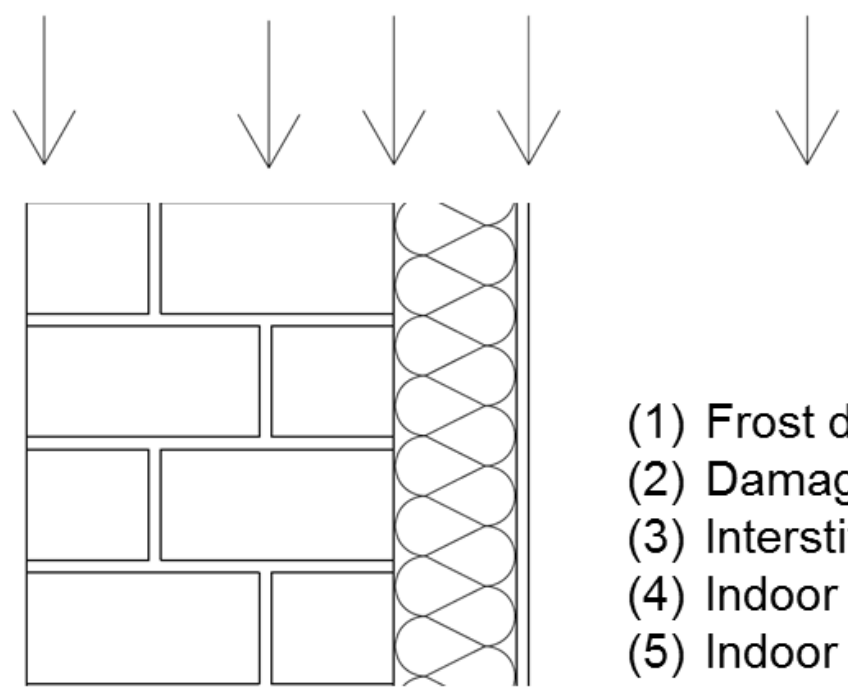
(1) Frost damage
(2) Damage wooden beam ends
(3) Interstitial condensation
(4) Indoor surface relative humidity
(5) Indoor relative humidity 
Postprint: Vereecken E, Van Gelder L, Janssen H, Roels S, 2015. Interior insulation for wall retrofitting - A probabilistic analysis of energy savings and hygrothermal risks. Energy and Buildings 89: 231-244. doi.org/10.1016/j.enbuild.2014.12.031

\section{Figure 2}

a)

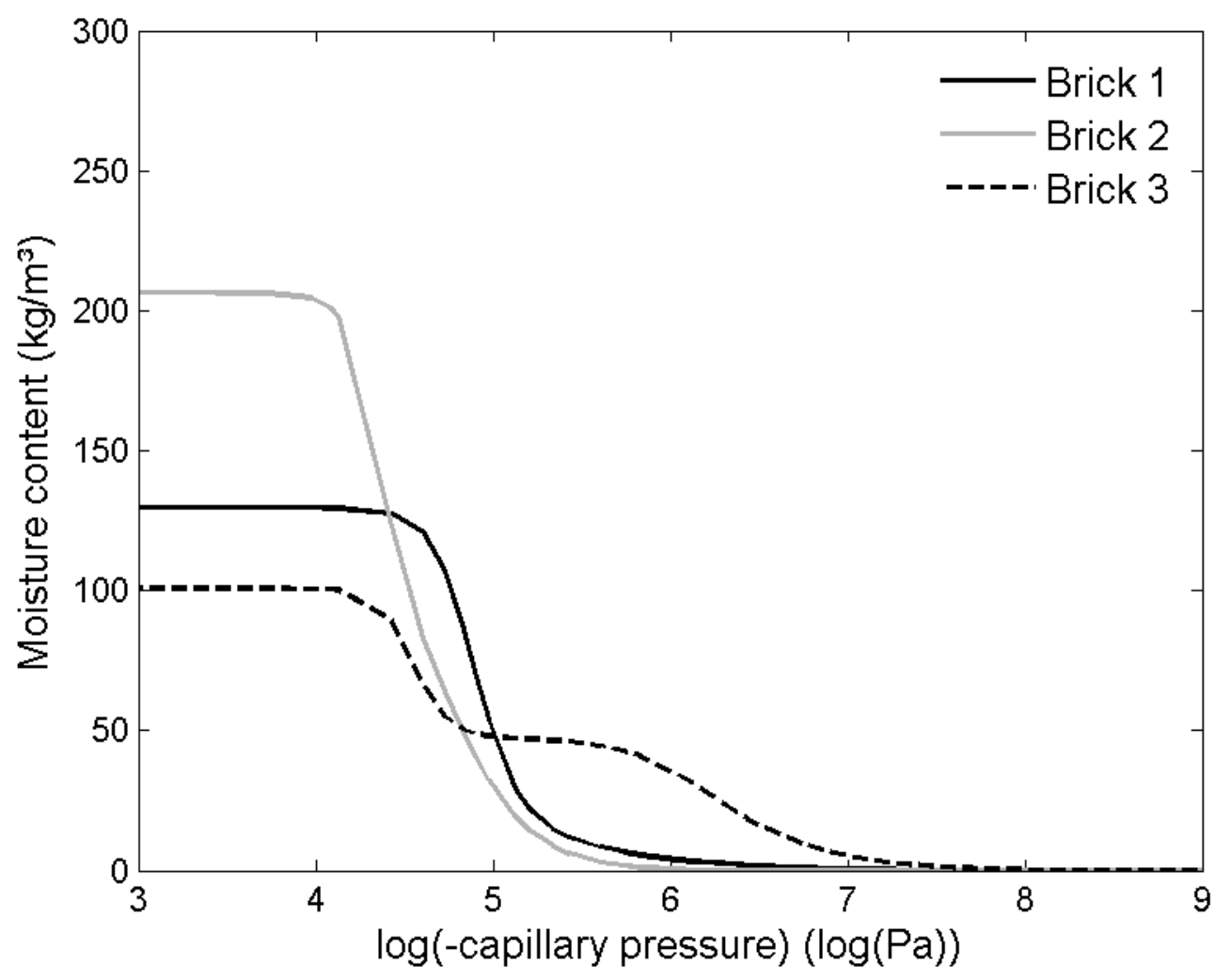


Postprint: Vereecken E, Van Gelder L, Janssen H, Roels S, 2015. Interior insulation for wall retrofitting - A probabilistic analysis of energy savings and hygrothermal risks. Energy and Buildings 89: 231-244. doi.org/10.1016/j.enbuild.2014.12.031

b)

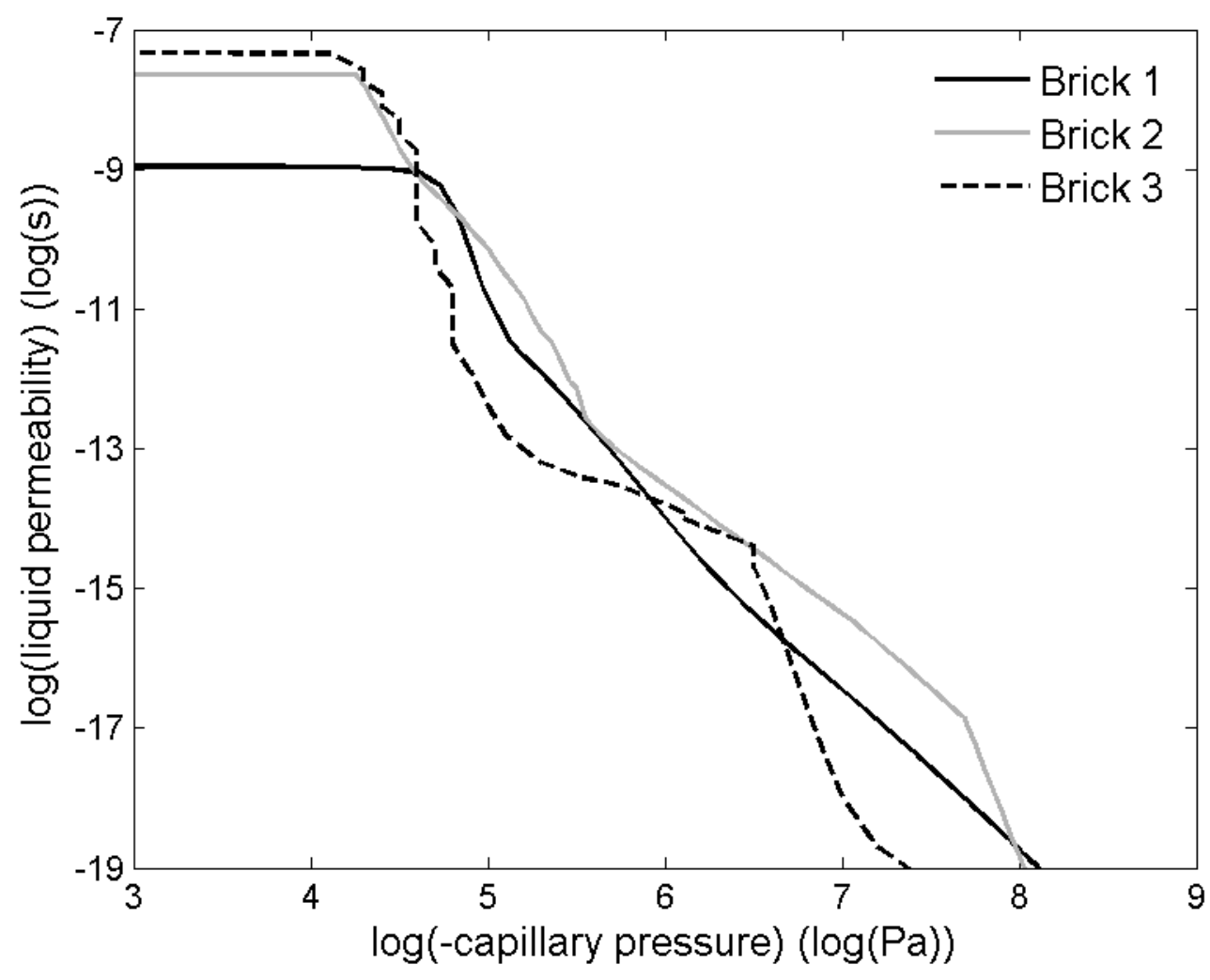


Postprint: Vereecken E, Van Gelder L, Janssen H, Roels S, 2015. Interior insulation for wall retrofitting - A probabilistic analysis of energy savings and hygrothermal risks. Energy and Buildings 89: 231-244. doi.org/10.1016/j.enbuild.2014.12.031

\section{Figure 3}

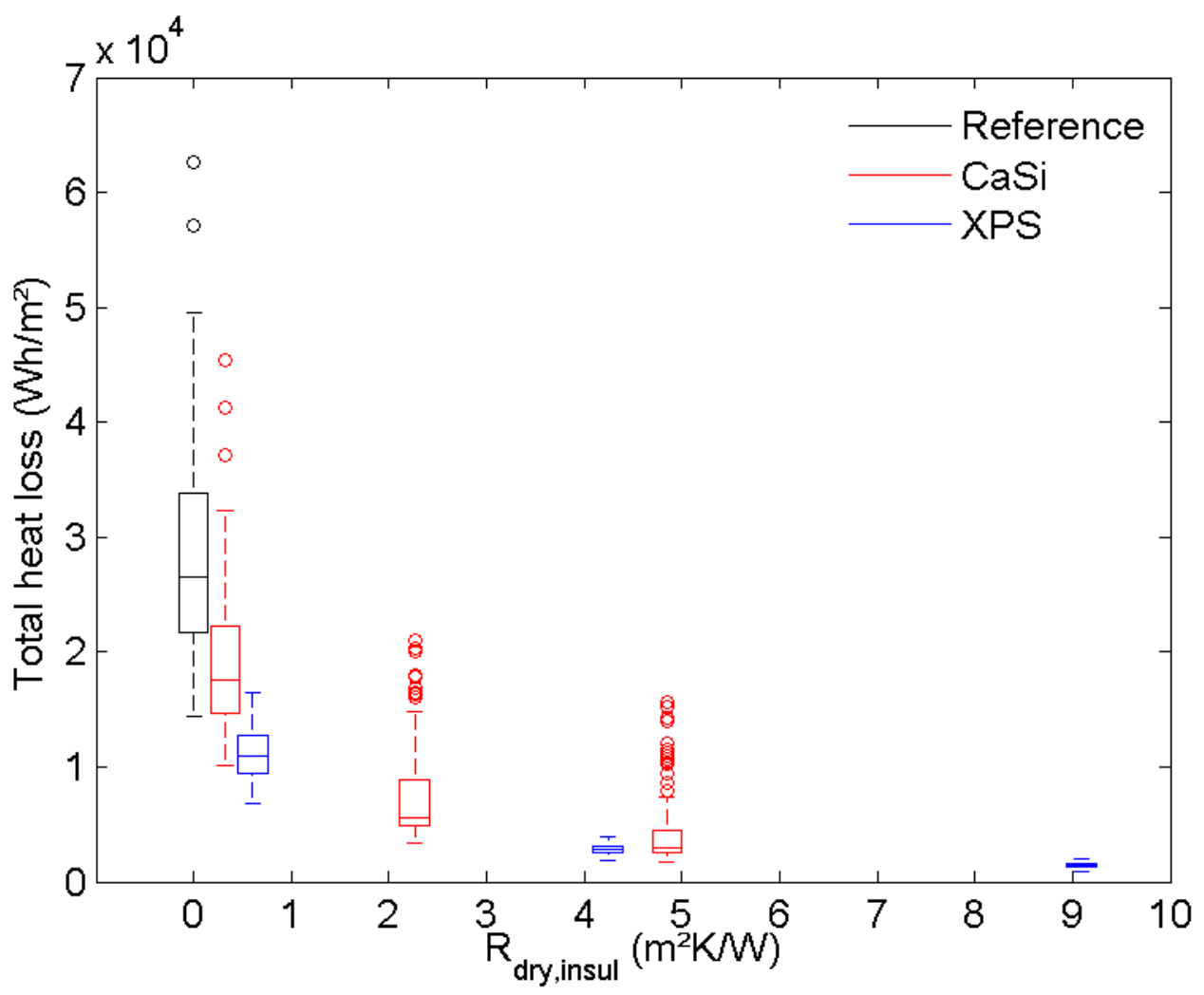


Postprint: Vereecken E, Van Gelder L, Janssen H, Roels S, 2015. Interior insulation for wall retrofitting - A probabilistic analysis of energy savings and hygrothermal risks. Energy and Buildings 89: 231-244. doi.org/10.1016/j.enbuild.2014.12.031

Figure 4

a)

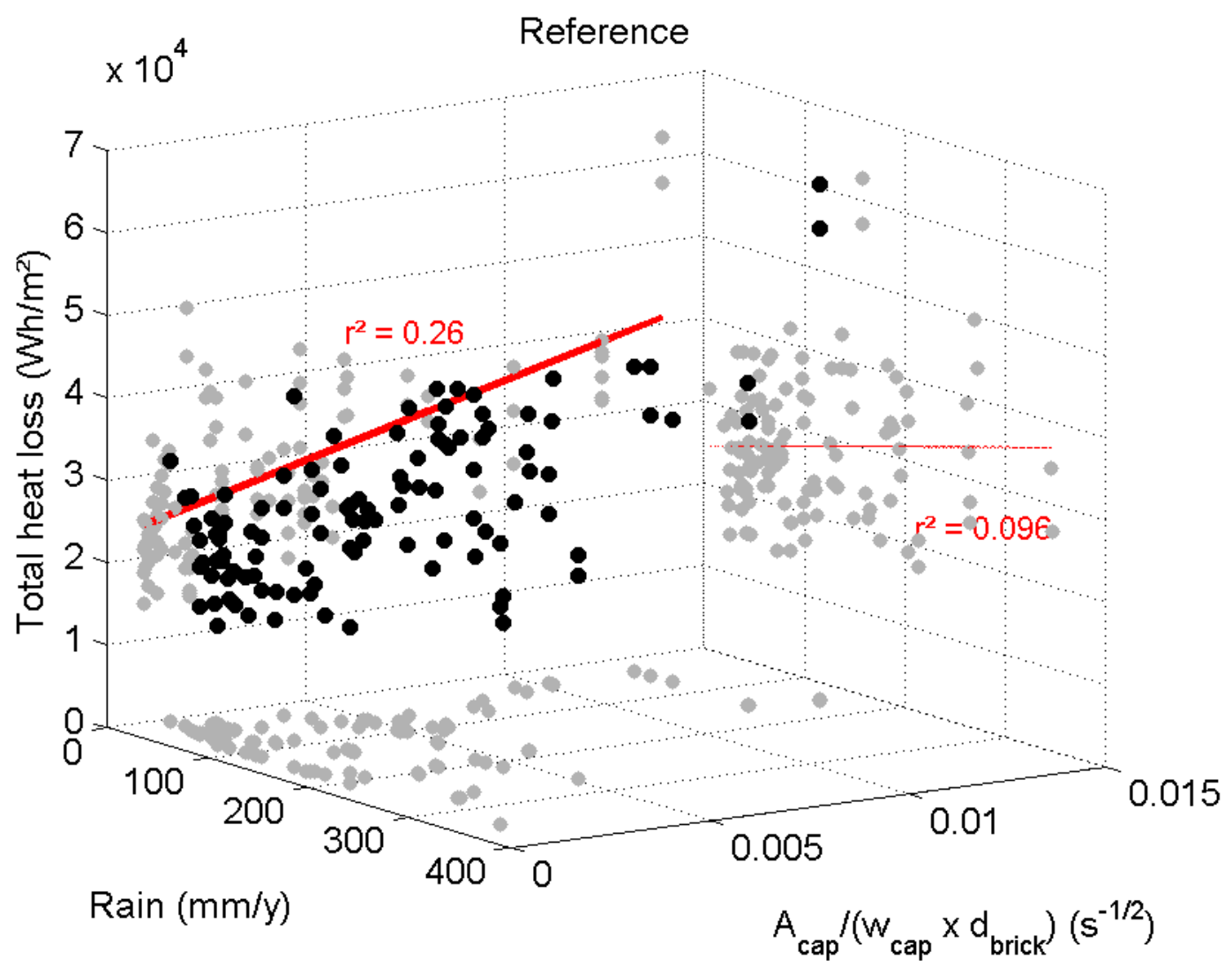


Postprint: Vereecken E, Van Gelder L, Janssen H, Roels S, 2015. Interior insulation for wall retrofitting - A probabilistic analysis of energy savings and hygrothermal risks. Energy and Buildings 89: 231-244. doi.org/10.1016/j.enbuild.2014.12.031

b)

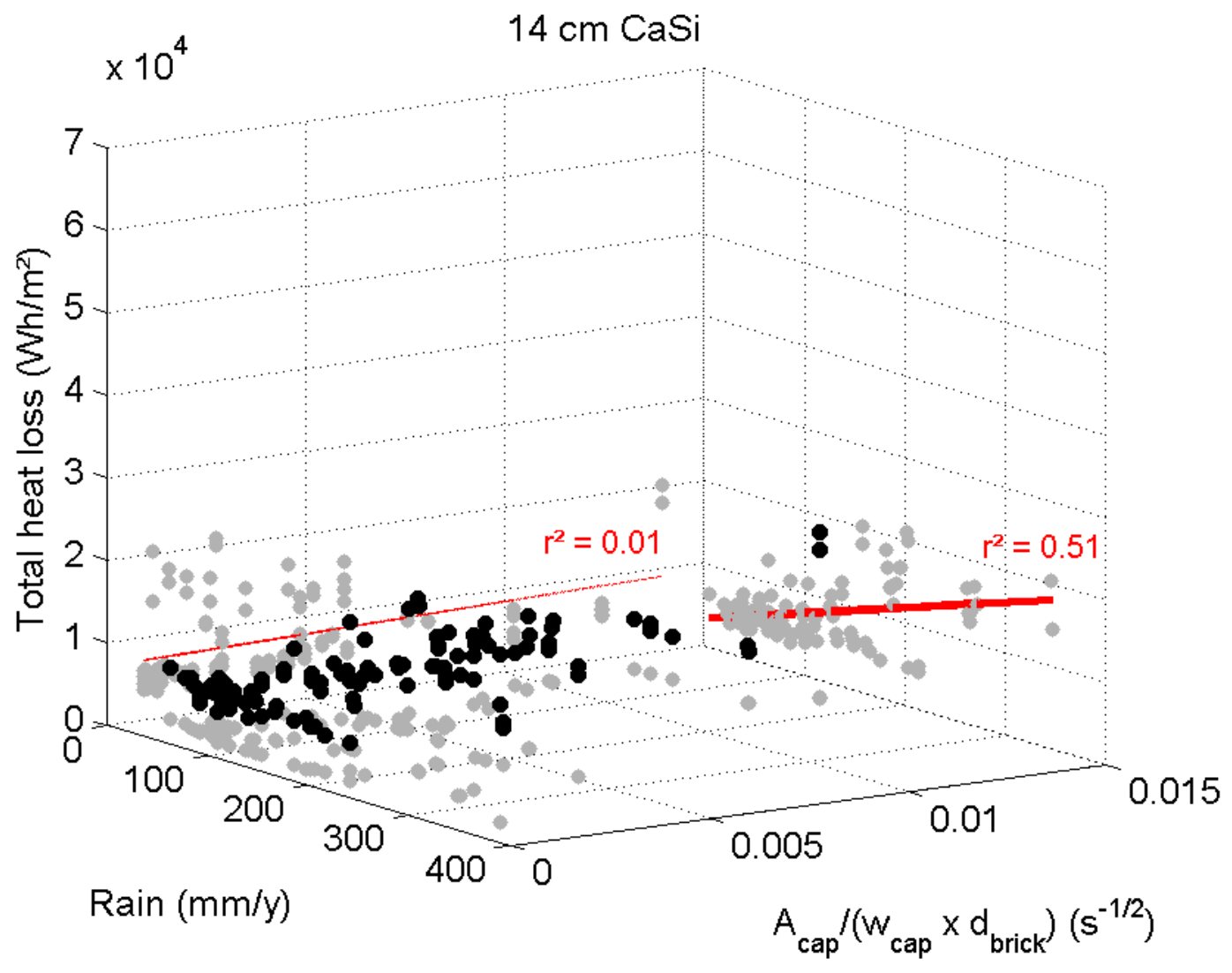


Postprint: Vereecken E, Van Gelder L, Janssen H, Roels S, 2015. Interior insulation for wall retrofitting - A probabilistic analysis of energy savings and hygrothermal risks. Energy and Buildings 89: 231-244. doi.org/10.1016/j.enbuild.2014.12.031

c)

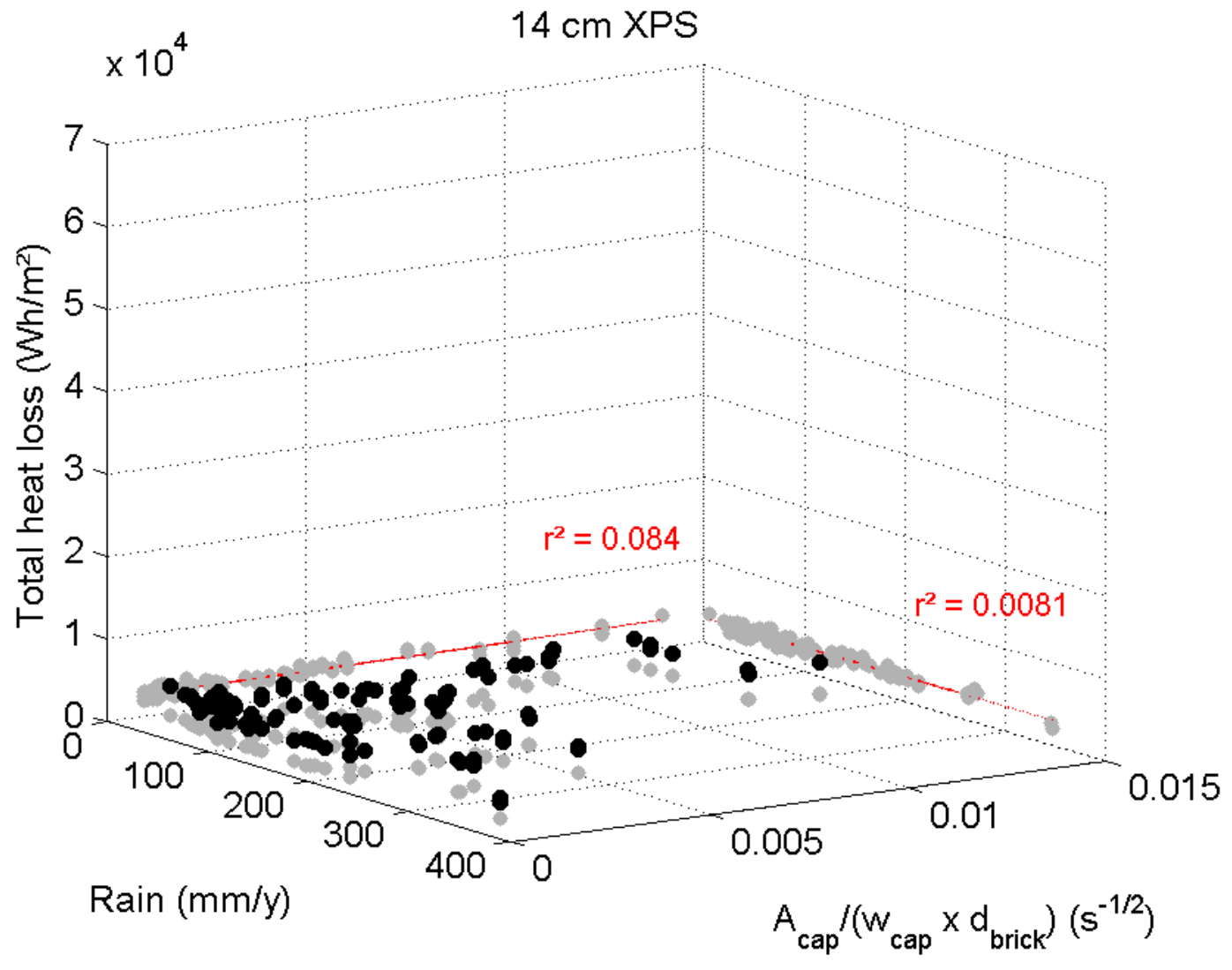


Postprint: Vereecken E, Van Gelder L, Janssen H, Roels S, 2015. Interior insulation for wall retrofitting - A probabilistic analysis of energy savings and hygrothermal risks. Energy and Buildings 89: 231-244. doi.org/10.1016/j.enbuild.2014.12.031

d)

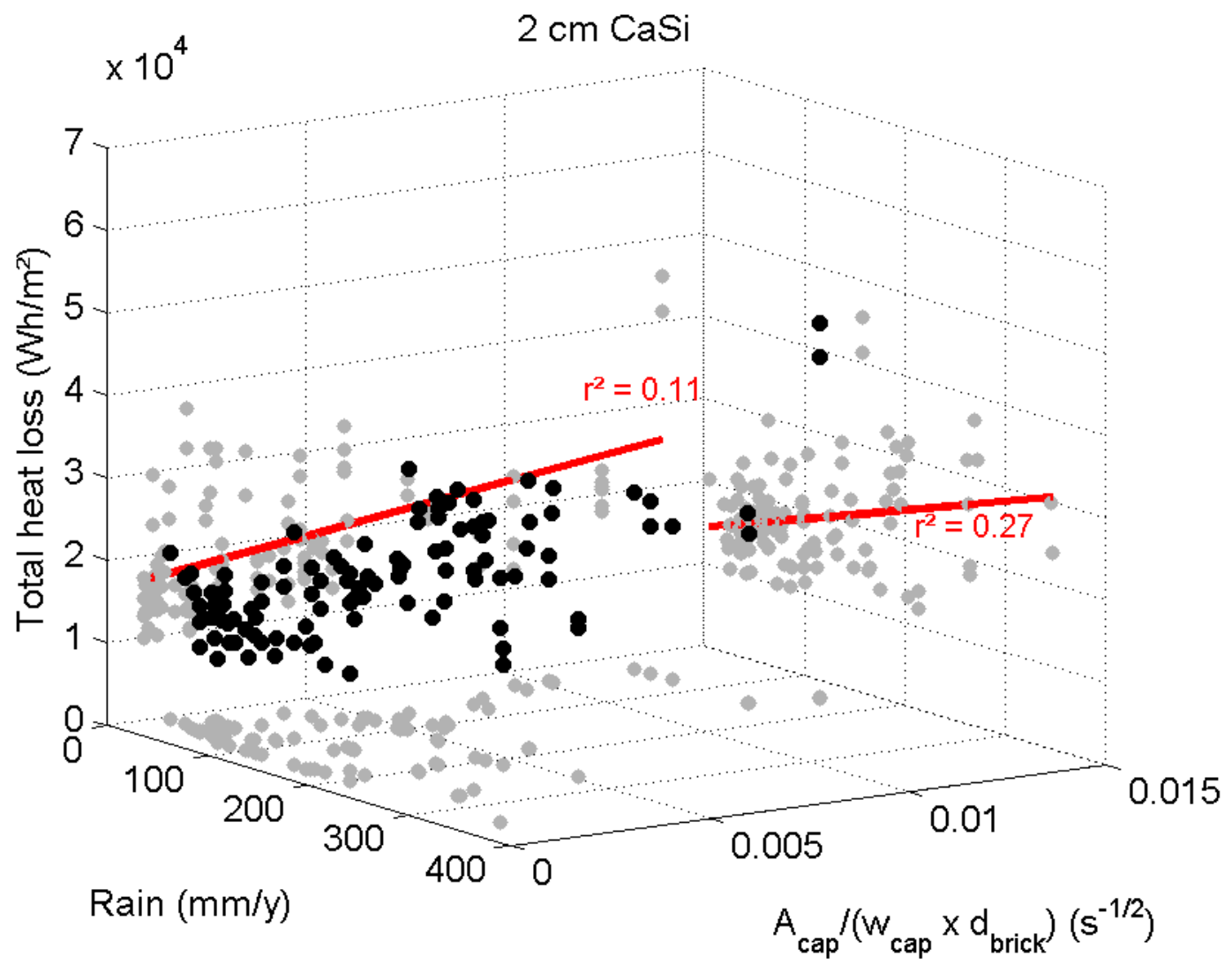


Postprint: Vereecken E, Van Gelder L, Janssen H, Roels S, 2015. Interior insulation for wall retrofitting - A probabilistic analysis of energy savings and hygrothermal risks. Energy and Buildings 89: 231-244. doi.org/10.1016/j.enbuild.2014.12.031

\section{Figure 5}

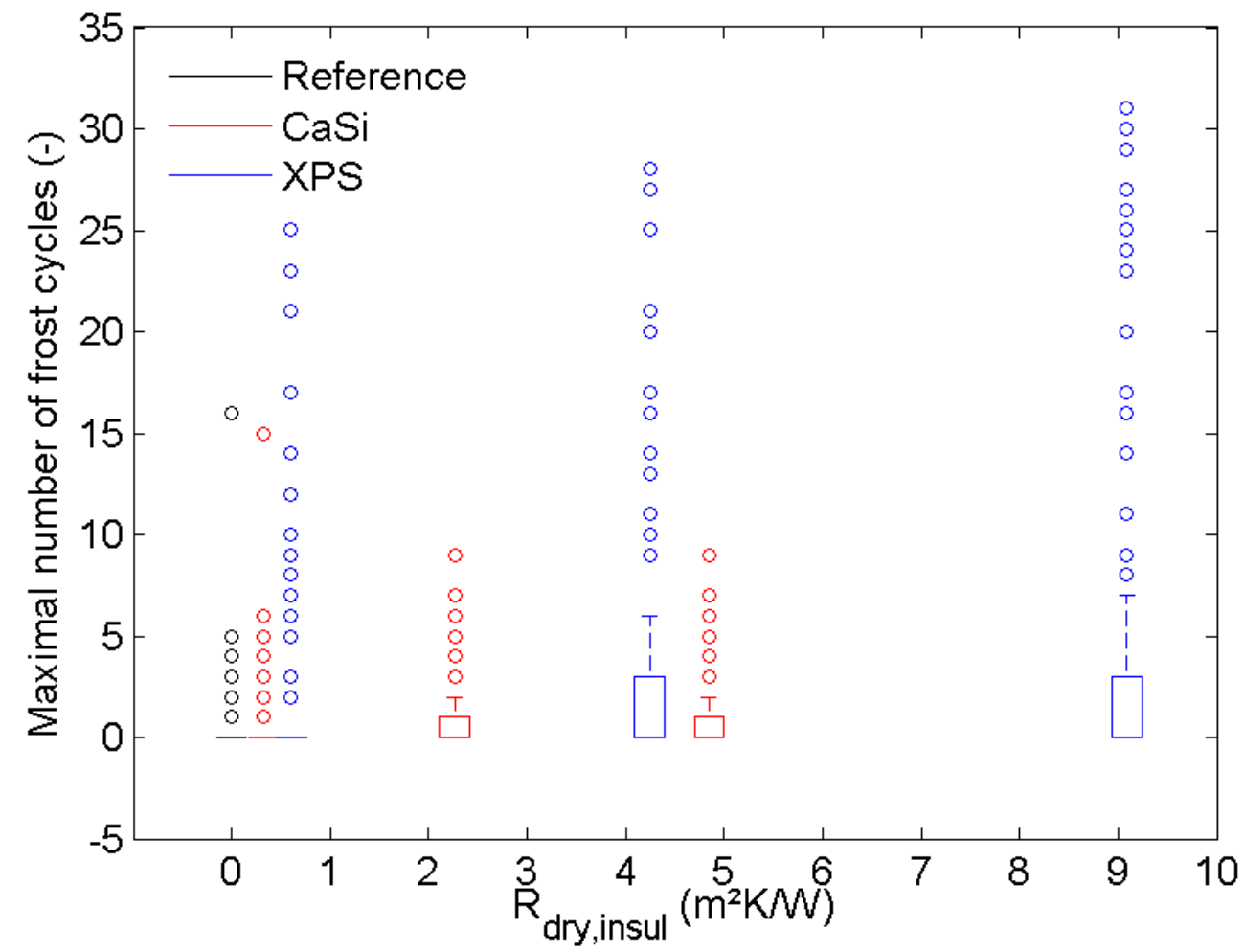


Postprint: Vereecken E, Van Gelder L, Janssen H, Roels S, 2015. Interior insulation for wall retrofitting - A probabilistic analysis of energy savings and hygrothermal risks. Energy and Buildings 89: 231-244. doi.org/10.1016/j.enbuild.2014.12.031

\section{Figure 6}

a)

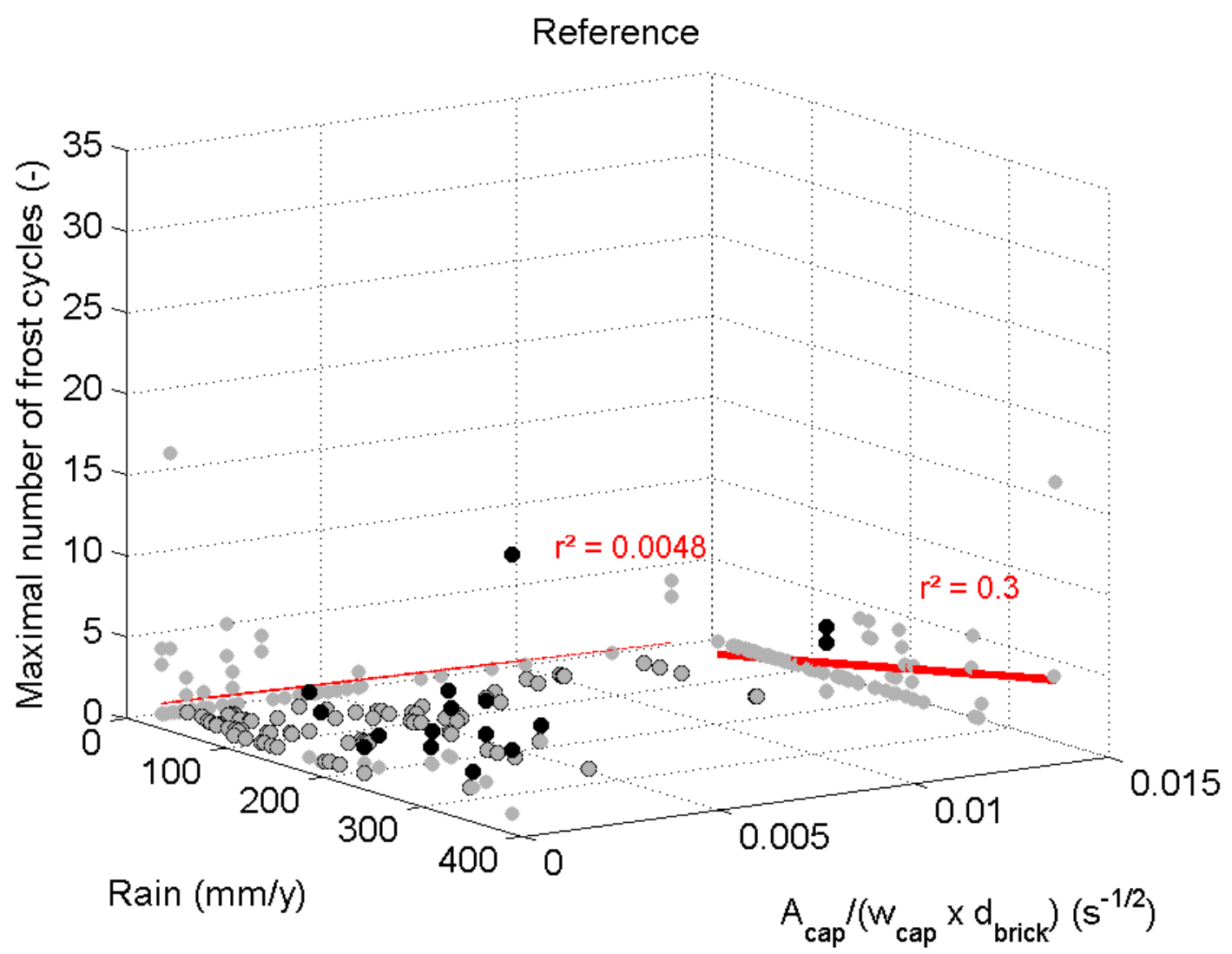


Postprint: Vereecken E, Van Gelder L, Janssen H, Roels S, 2015. Interior insulation for wall retrofitting - A probabilistic analysis of energy savings and hygrothermal risks. Energy and Buildings 89: 231-244. doi.org/10.1016/j.enbuild.2014.12.031

b)

\section{$14 \mathrm{~cm} \mathrm{CaSi}$}

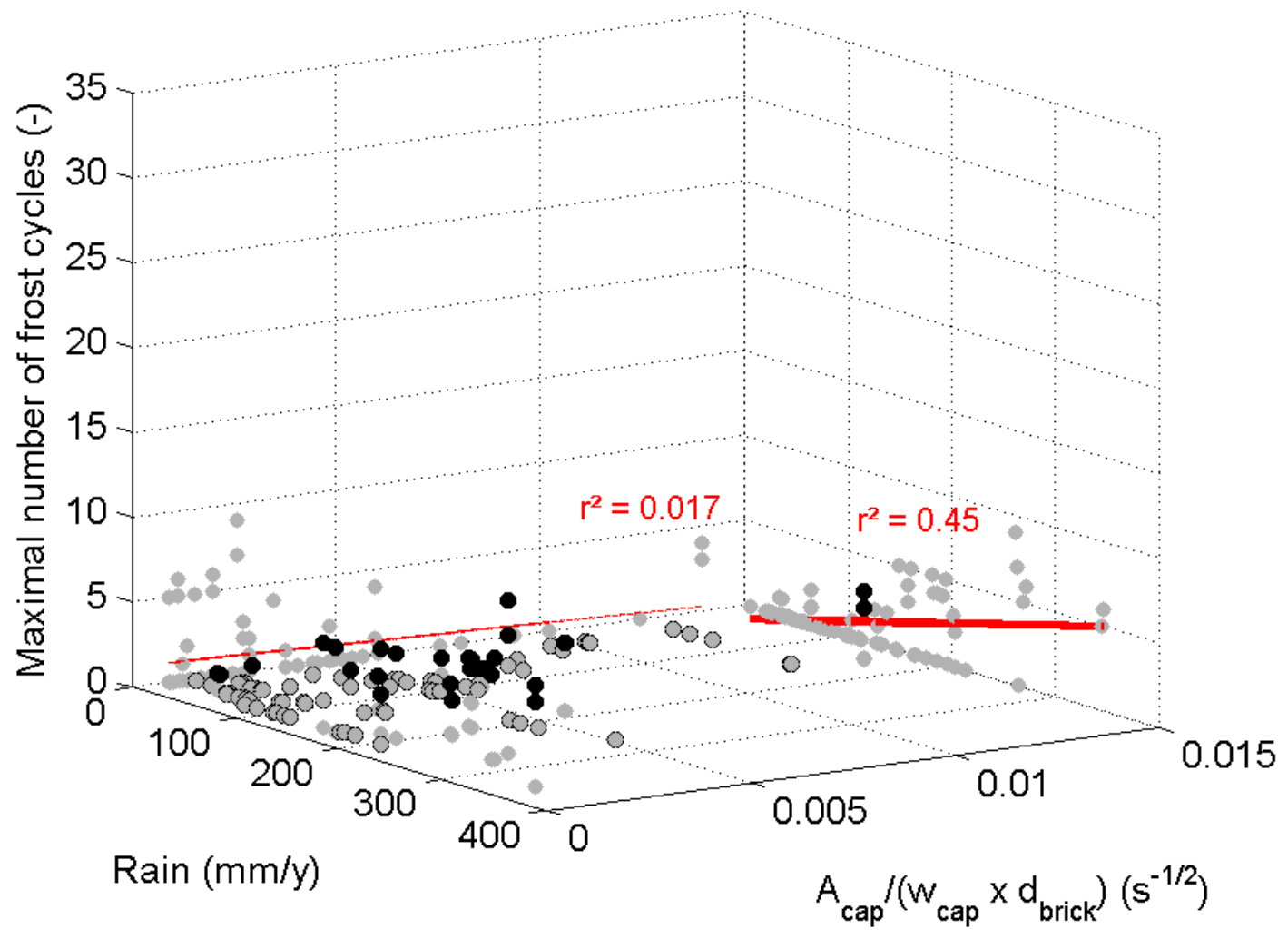


Postprint: Vereecken E, Van Gelder L, Janssen H, Roels S, 2015. Interior insulation for wall retrofitting - A probabilistic analysis of energy savings and hygrothermal risks. Energy and Buildings 89: 231-244. doi.org/10.1016/j.enbuild.2014.12.031

c)

\section{$14 \mathrm{~cm}$ XPS}

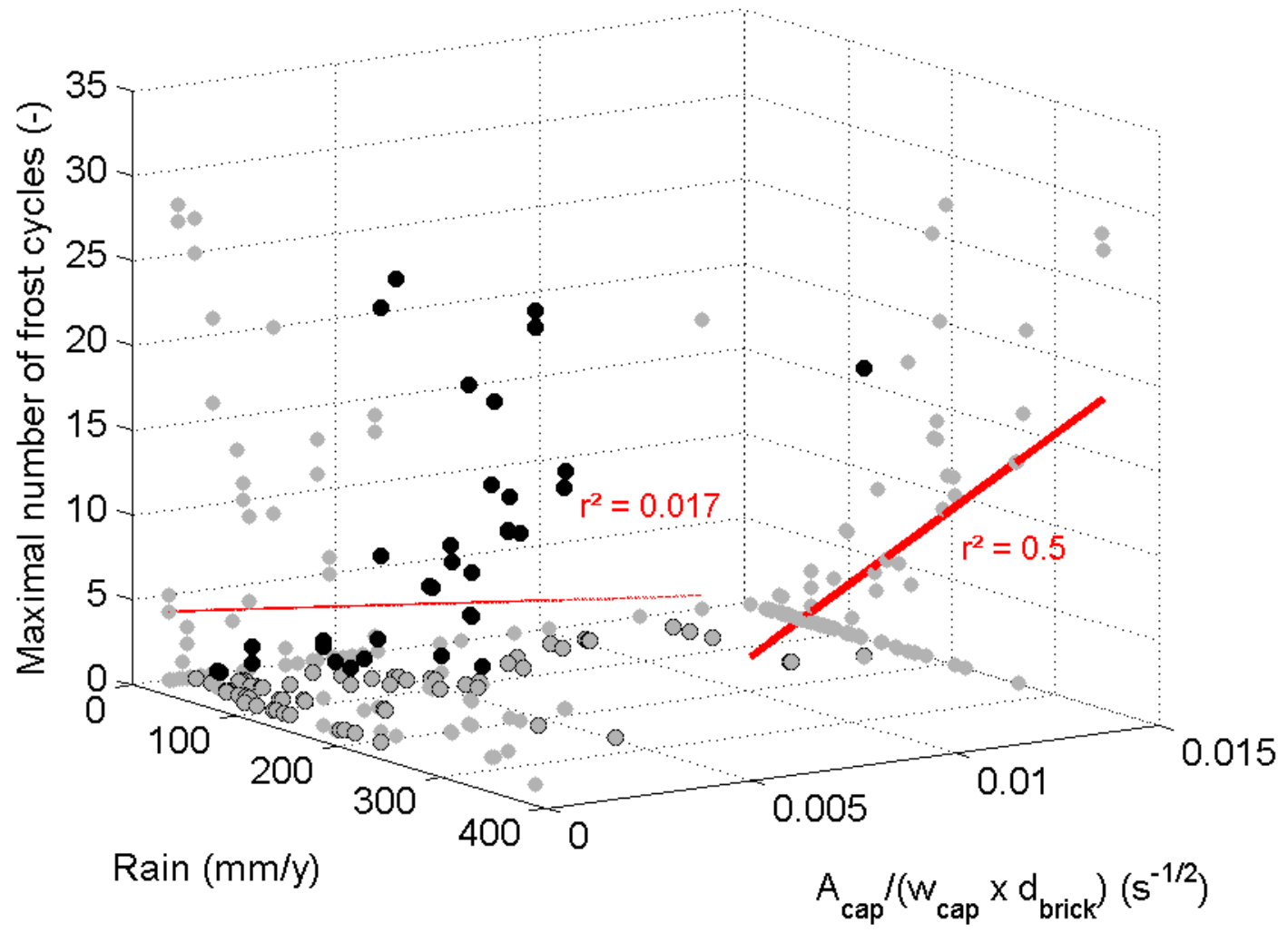


Postprint: Vereecken E, Van Gelder L, Janssen H, Roels S, 2015. Interior insulation for wall retrofitting - A probabilistic analysis of energy savings and hygrothermal risks. Energy and Buildings 89: 231-244. doi.org/10.1016/j.enbuild.2014.12.031

\section{Figure 7}

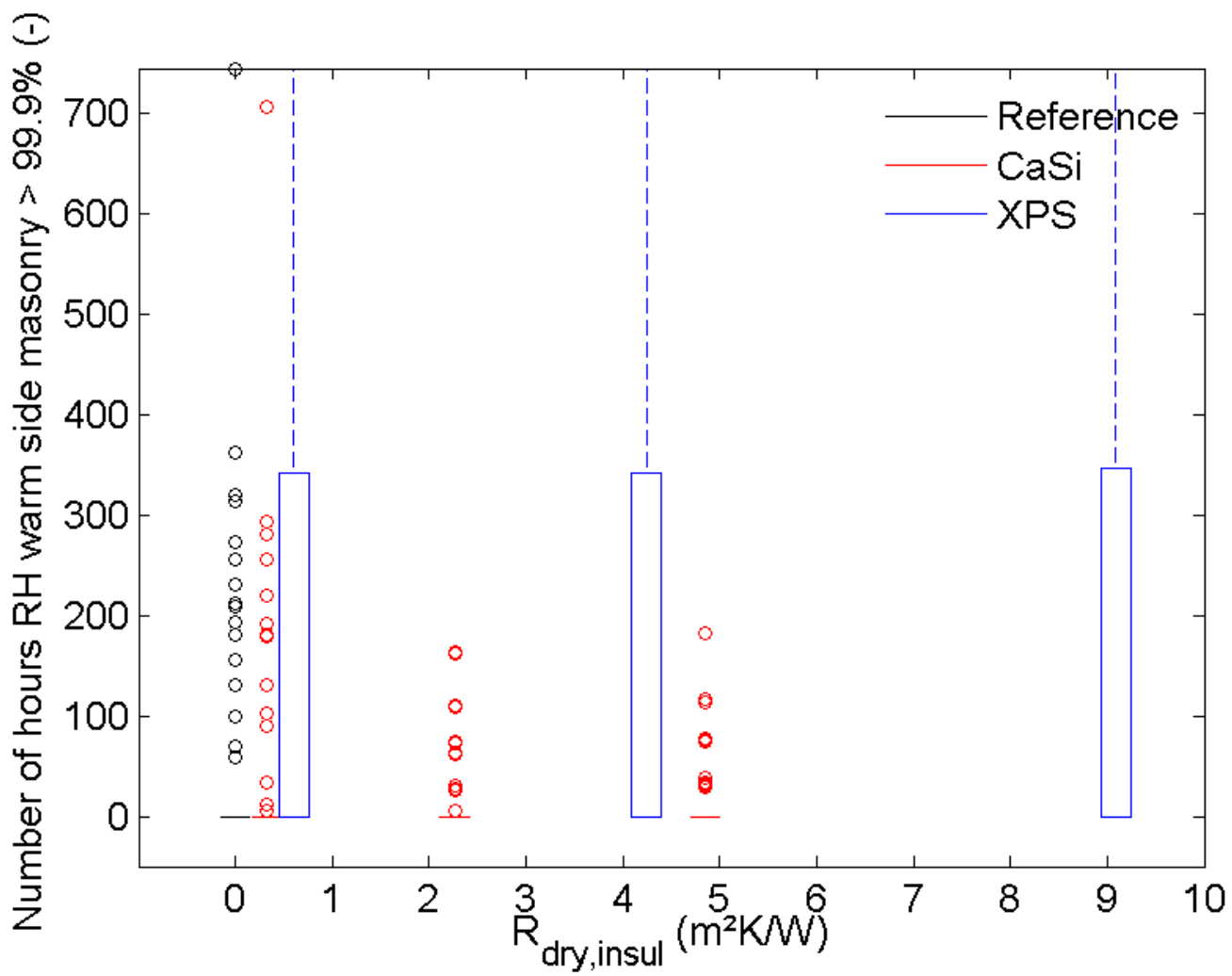


Postprint: Vereecken E, Van Gelder L, Janssen H, Roels S, 2015. Interior insulation for wall retrofitting - A probabilistic analysis of energy savings and hygrothermal risks. Energy and Buildings 89: 231-244. doi.org/10.1016/j.enbuild.2014.12.031

\section{Figure 8}

a)

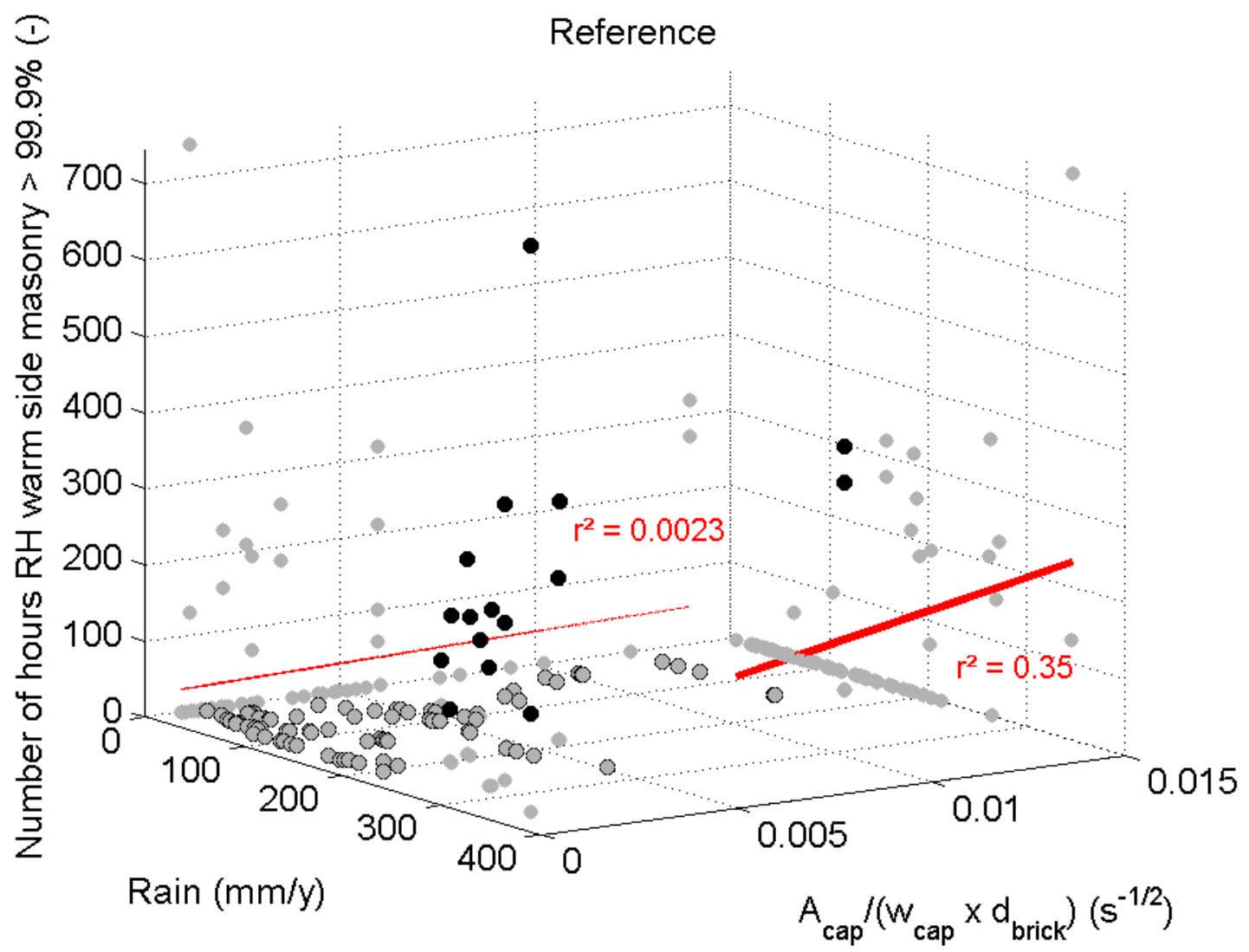


Postprint: Vereecken E, Van Gelder L, Janssen H, Roels S, 2015. Interior insulation for wall retrofitting - A probabilistic analysis of energy savings and hygrothermal risks. Energy and Buildings 89: 231-244. doi.org/10.1016/j.enbuild.2014.12.031

b)

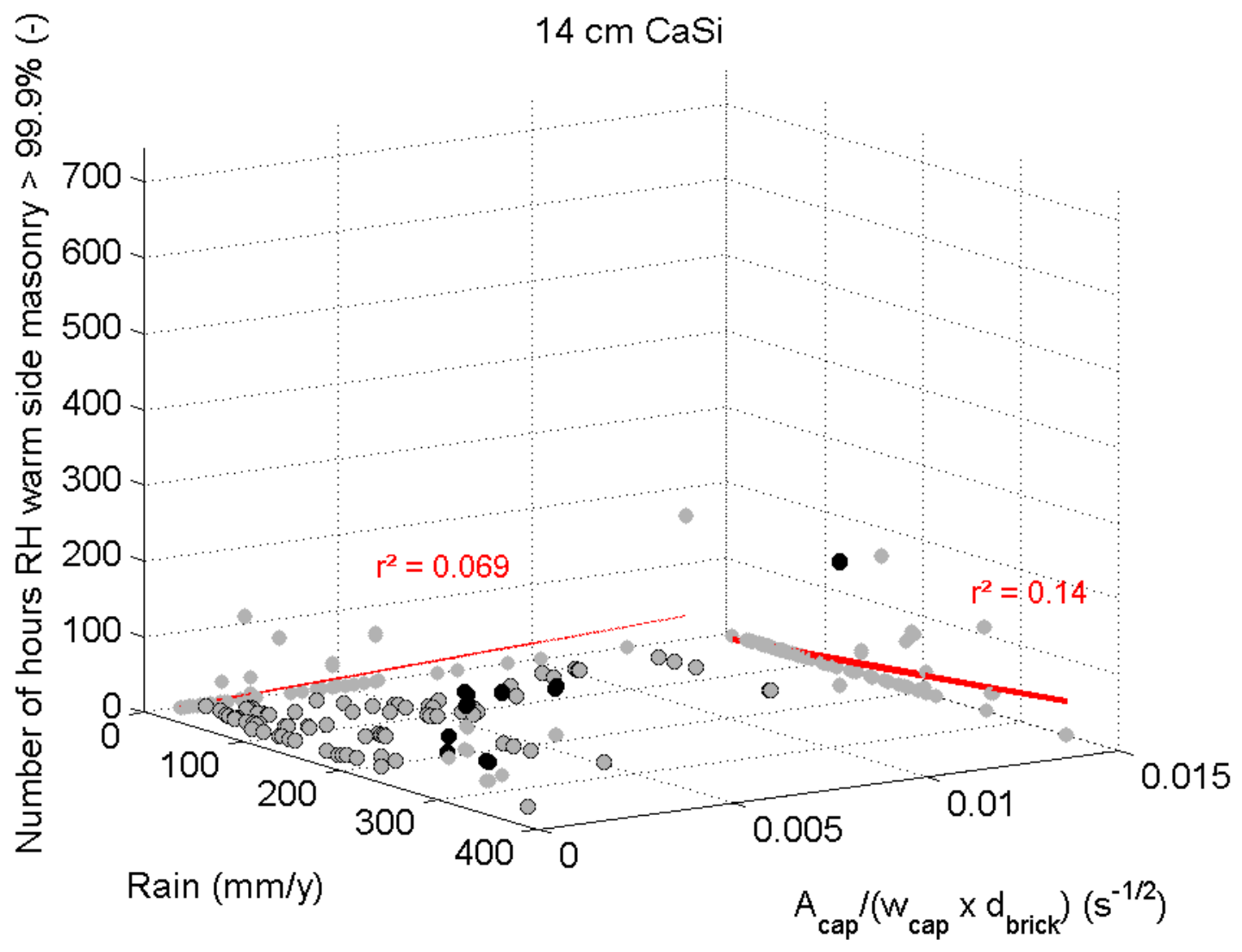


Postprint: Vereecken E, Van Gelder L, Janssen H, Roels S, 2015. Interior insulation for wall retrofitting - A probabilistic analysis of energy savings and hygrothermal risks. Energy and Buildings 89: 231-244. doi.org/10.1016/j.enbuild.2014.12.031

c)

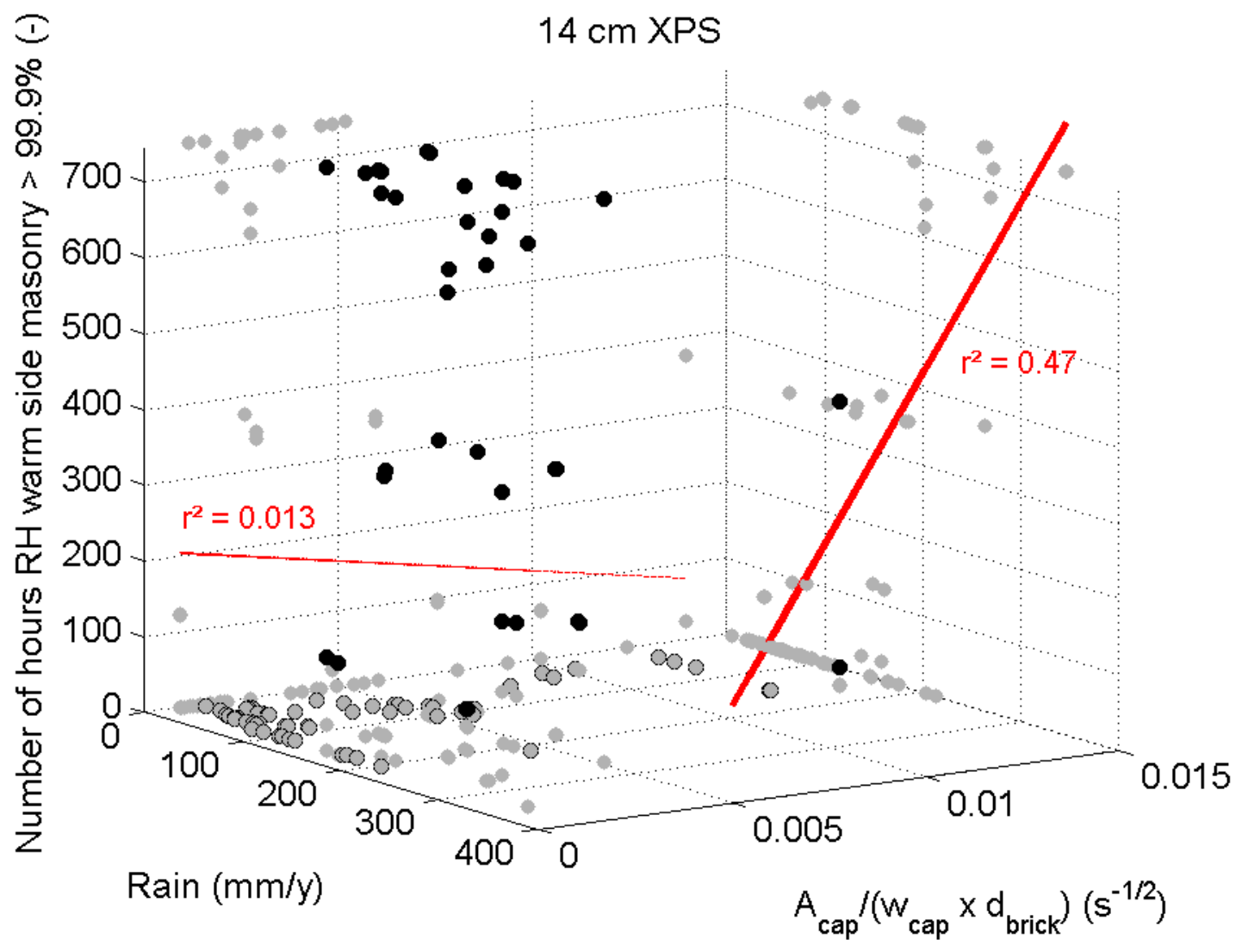


Postprint: Vereecken E, Van Gelder L, Janssen H, Roels S, 2015. Interior insulation for wall retrofitting - A probabilistic analysis of energy savings and hygrothermal risks. Energy and Buildings 89: 231-244. doi.org/10.1016/j.enbuild.2014.12.031

Figure 9

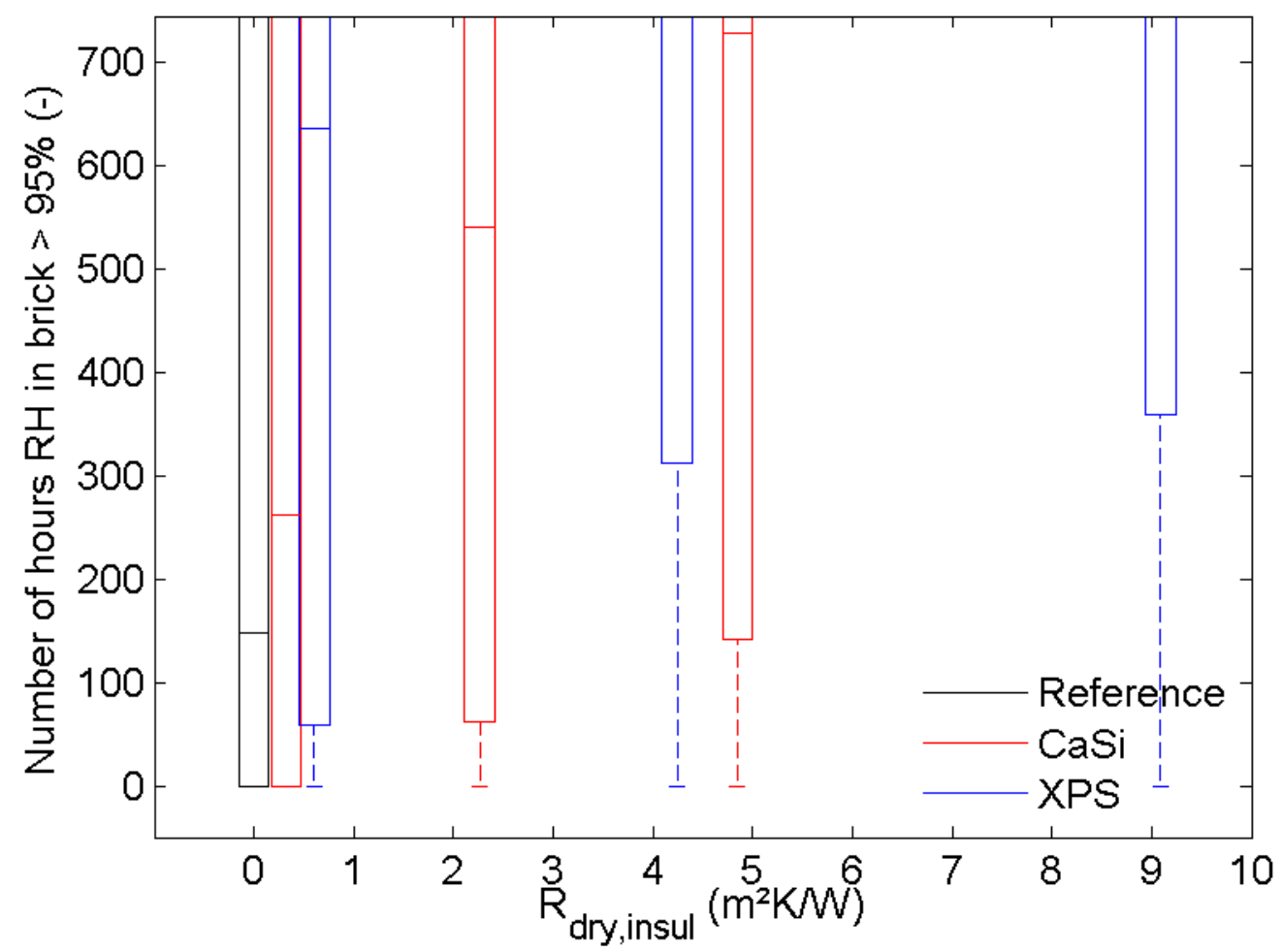


Postprint: Vereecken E, Van Gelder L, Janssen H, Roels S, 2015. Interior insulation for wall retrofitting - A probabilistic analysis of energy savings and hygrothermal risks. Energy and Buildings 89: 231-244. doi.org/10.1016/j.enbuild.2014.12.031

Figure 10

a)

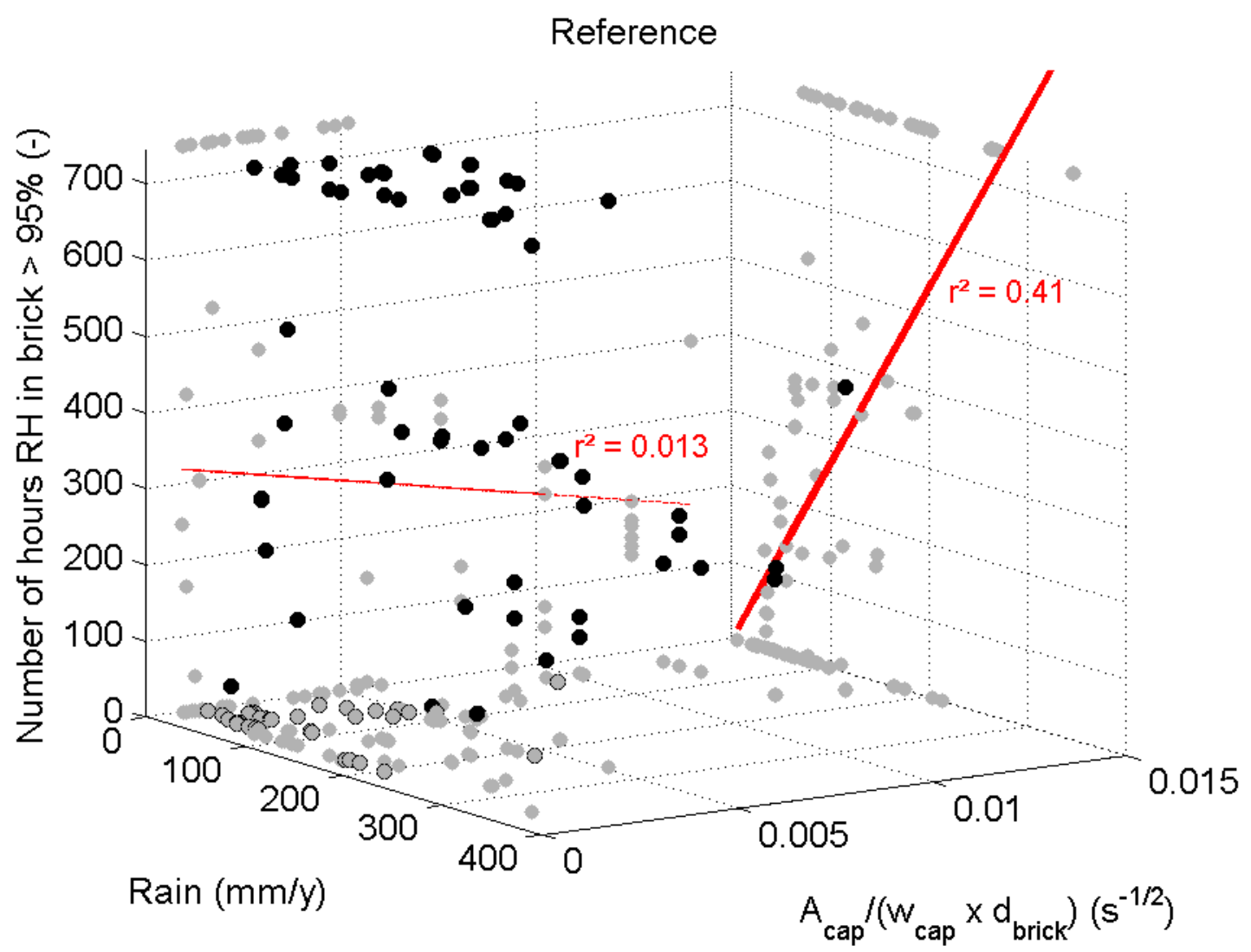


Postprint: Vereecken E, Van Gelder L, Janssen H, Roels S, 2015. Interior insulation for wall retrofitting - A probabilistic analysis of energy savings and hygrothermal risks. Energy and Buildings 89: 231-244. doi.org/10.1016/j.enbuild.2014.12.031

b)

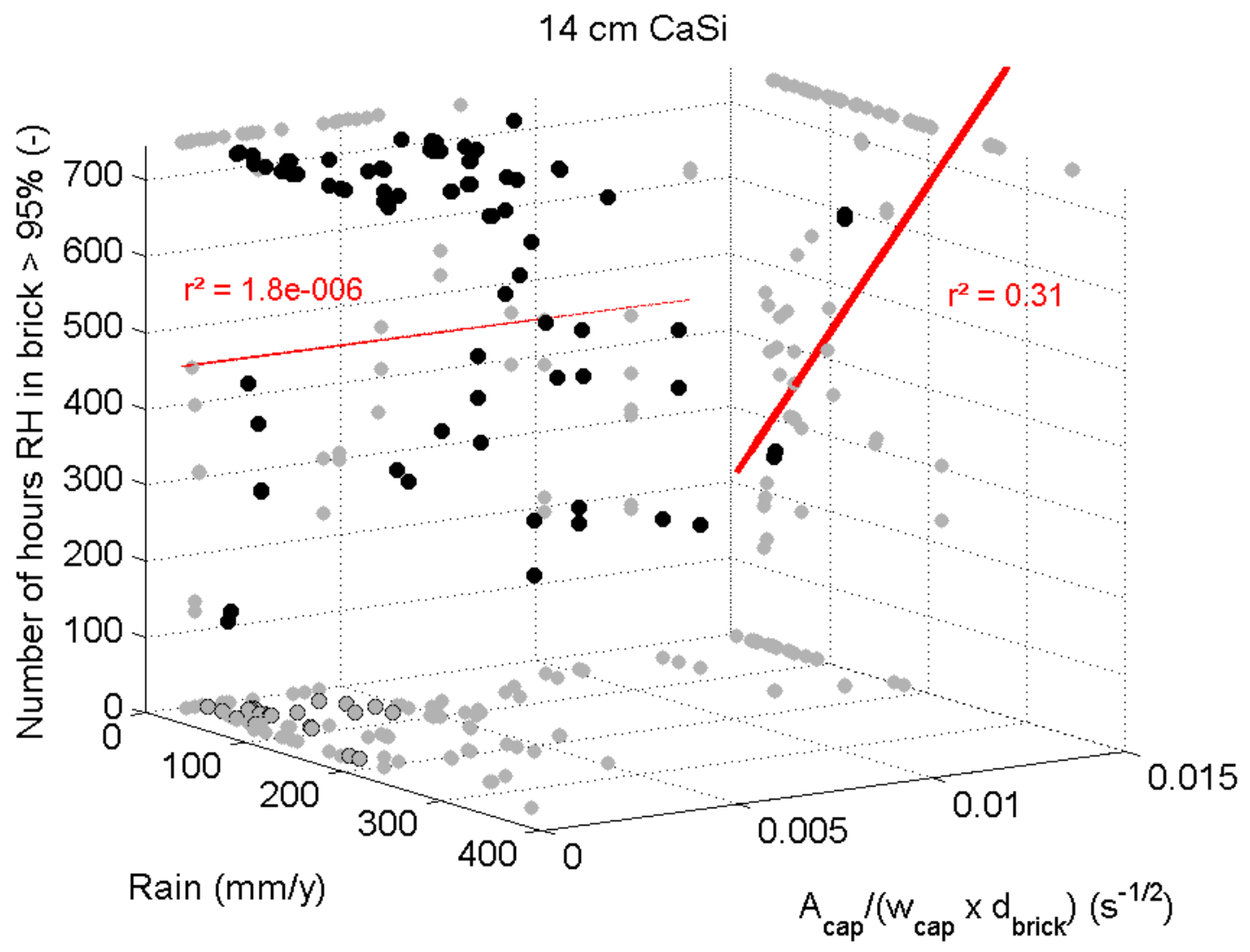


Postprint: Vereecken E, Van Gelder L, Janssen H, Roels S, 2015. Interior insulation for wall retrofitting - A probabilistic analysis of energy savings and hygrothermal risks. Energy and Buildings 89: 231-244. doi.org/10.1016/j.enbuild.2014.12.031

c)

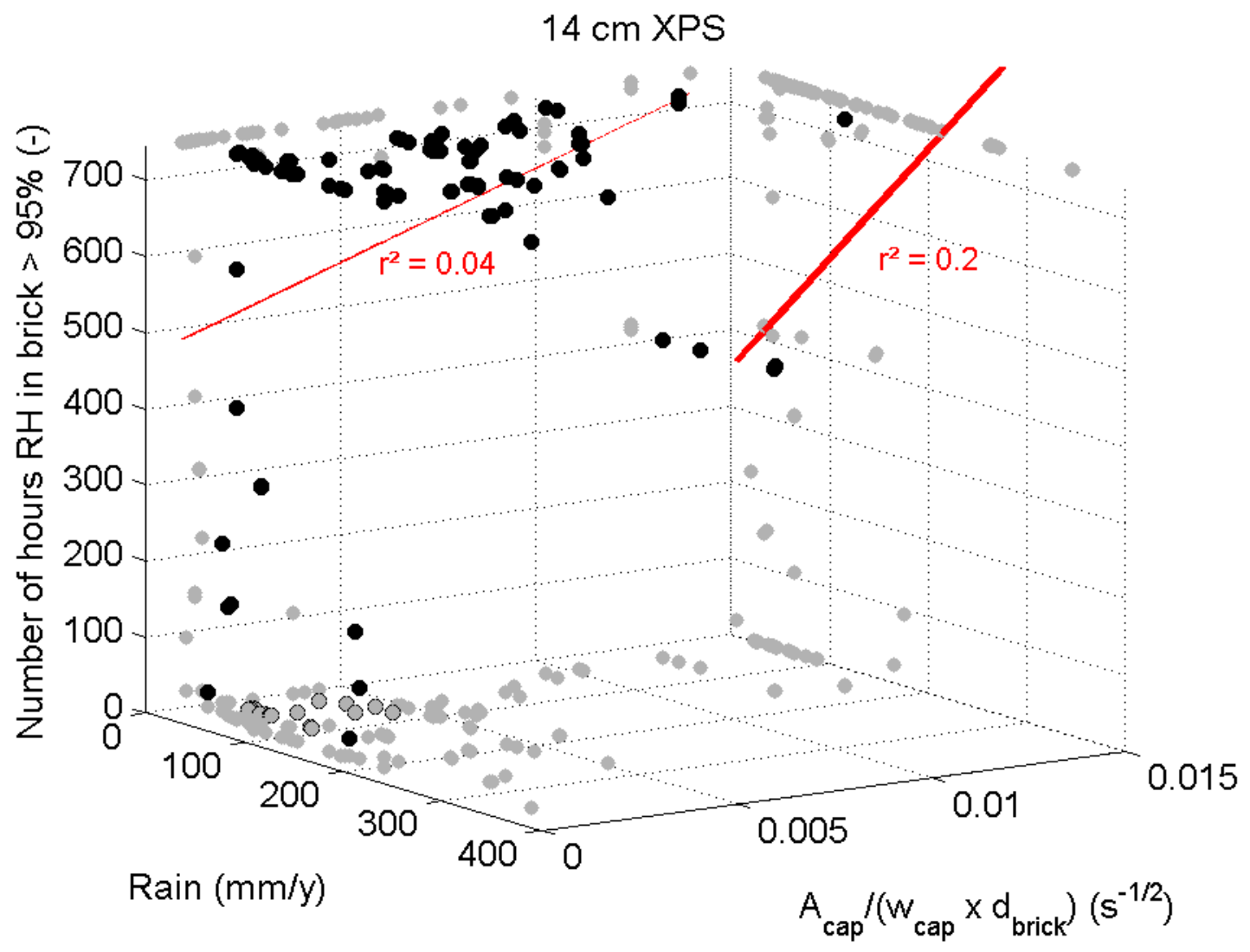


Postprint: Vereecken E, Van Gelder L, Janssen H, Roels S, 2015. Interior insulation for wall retrofitting - A probabilistic analysis of energy savings and hygrothermal risks. Energy and Buildings 89: 231-244. doi.org/10.1016/j.enbuild.2014.12.031

\section{Figure 11}

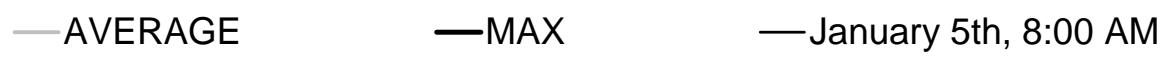

a)

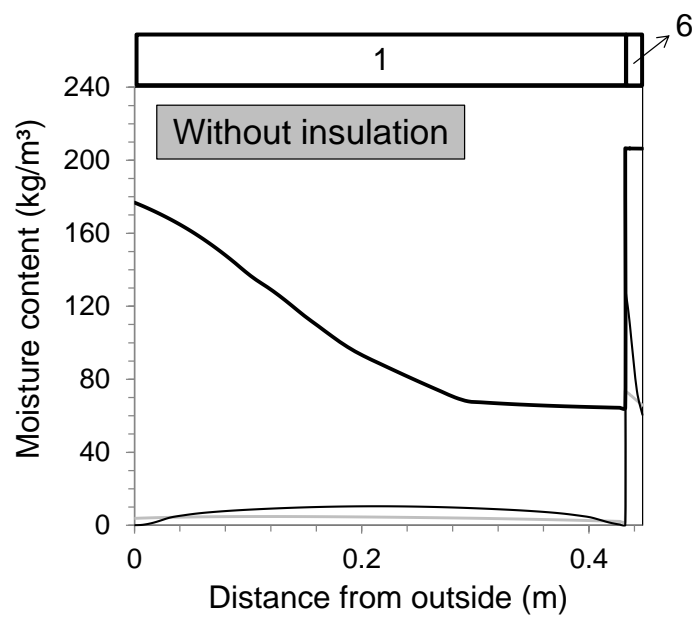

b)

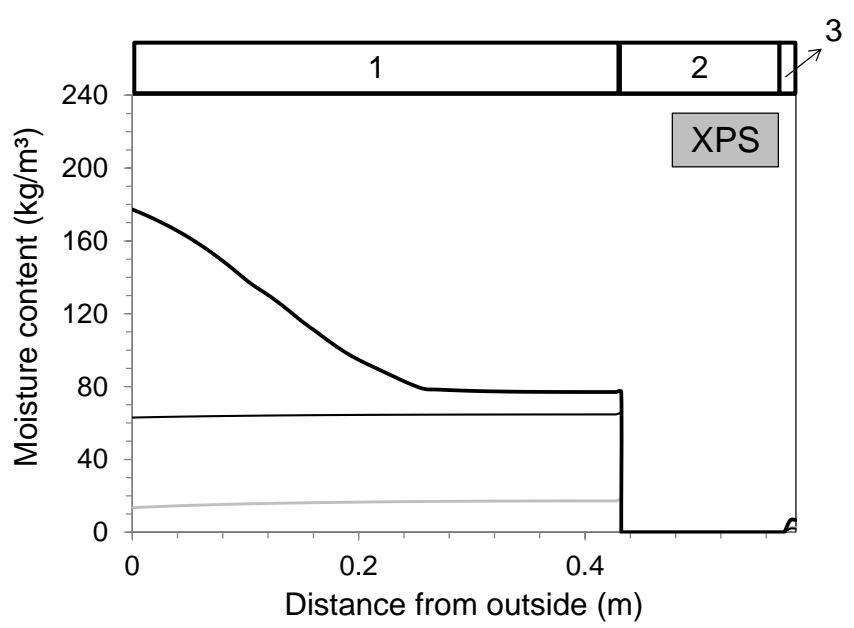

c)

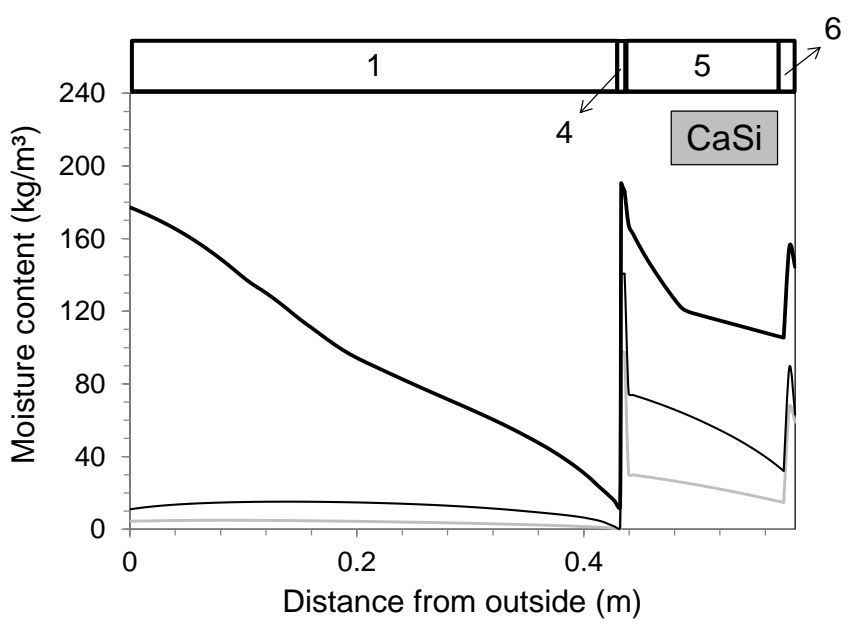


Postprint: Vereecken E, Van Gelder L, Janssen H, Roels S, 2015. Interior insulation for wall retrofitting - A probabilistic analysis of energy savings and hygrothermal risks. Energy and Buildings 89: 231-244. doi.org/10.1016/j.enbuild.2014.12.031

\section{Figure 12}

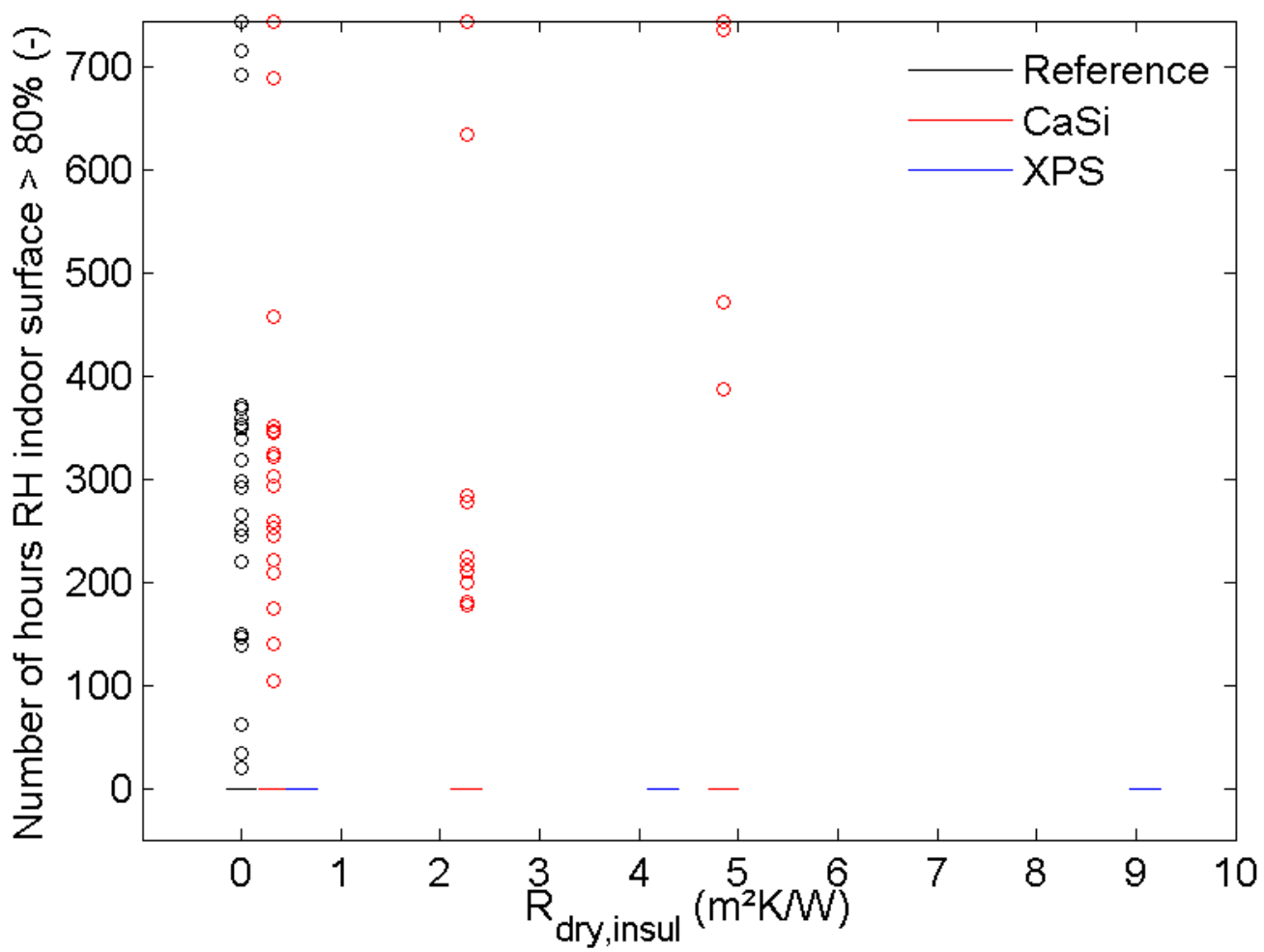


Postprint: Vereecken E, Van Gelder L, Janssen H, Roels S, 2015. Interior insulation for wall retrofitting - A probabilistic analysis of energy savings and hygrothermal risks. Energy and Buildings 89: 231-244. doi.org/10.1016/j.enbuild.2014.12.031

\section{Figure 13}

a)

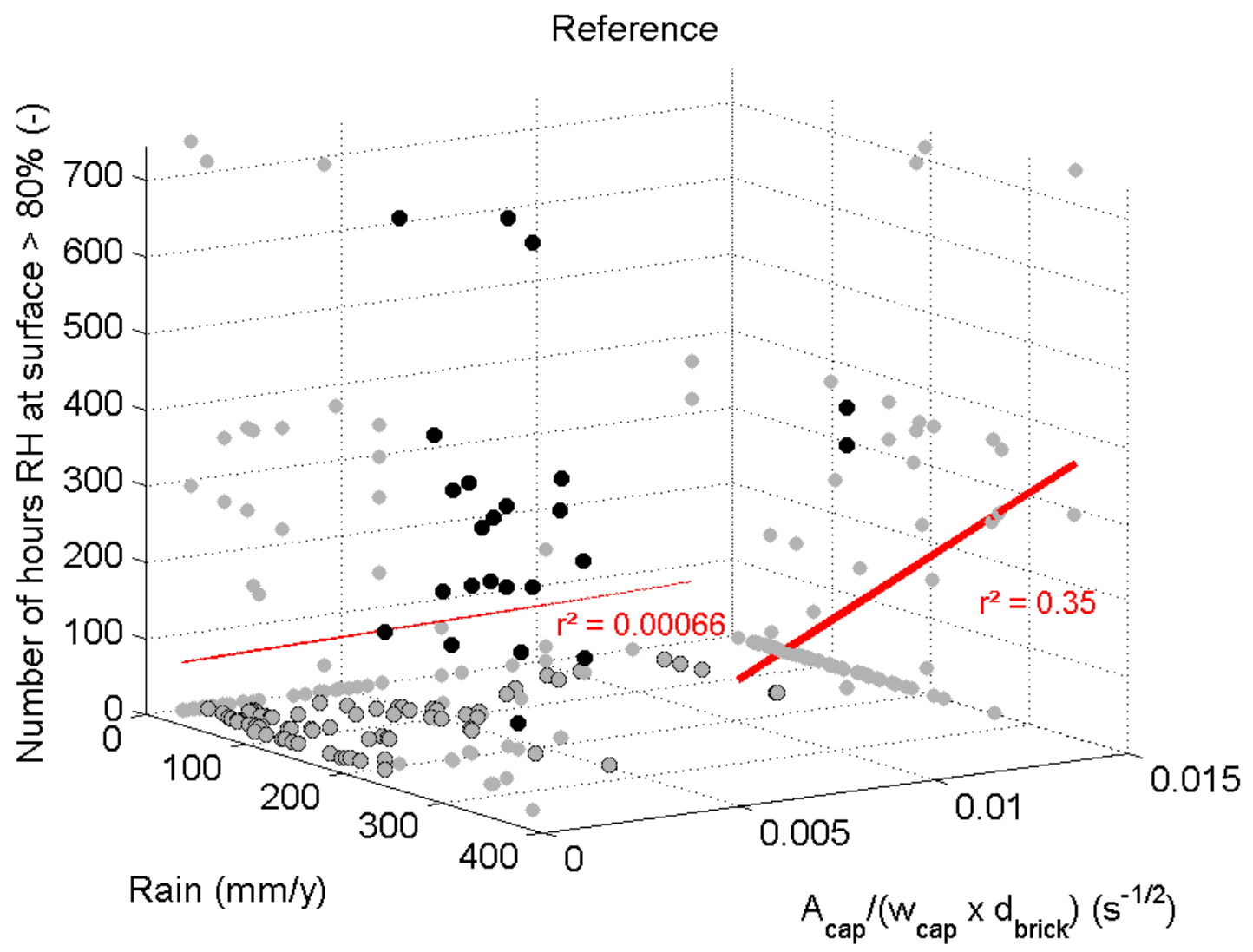


Postprint: Vereecken E, Van Gelder L, Janssen H, Roels S, 2015. Interior insulation for wall retrofitting - A probabilistic analysis of energy savings and hygrothermal risks. Energy and Buildings 89: 231-244. doi.org/10.1016/j.enbuild.2014.12.031

b)

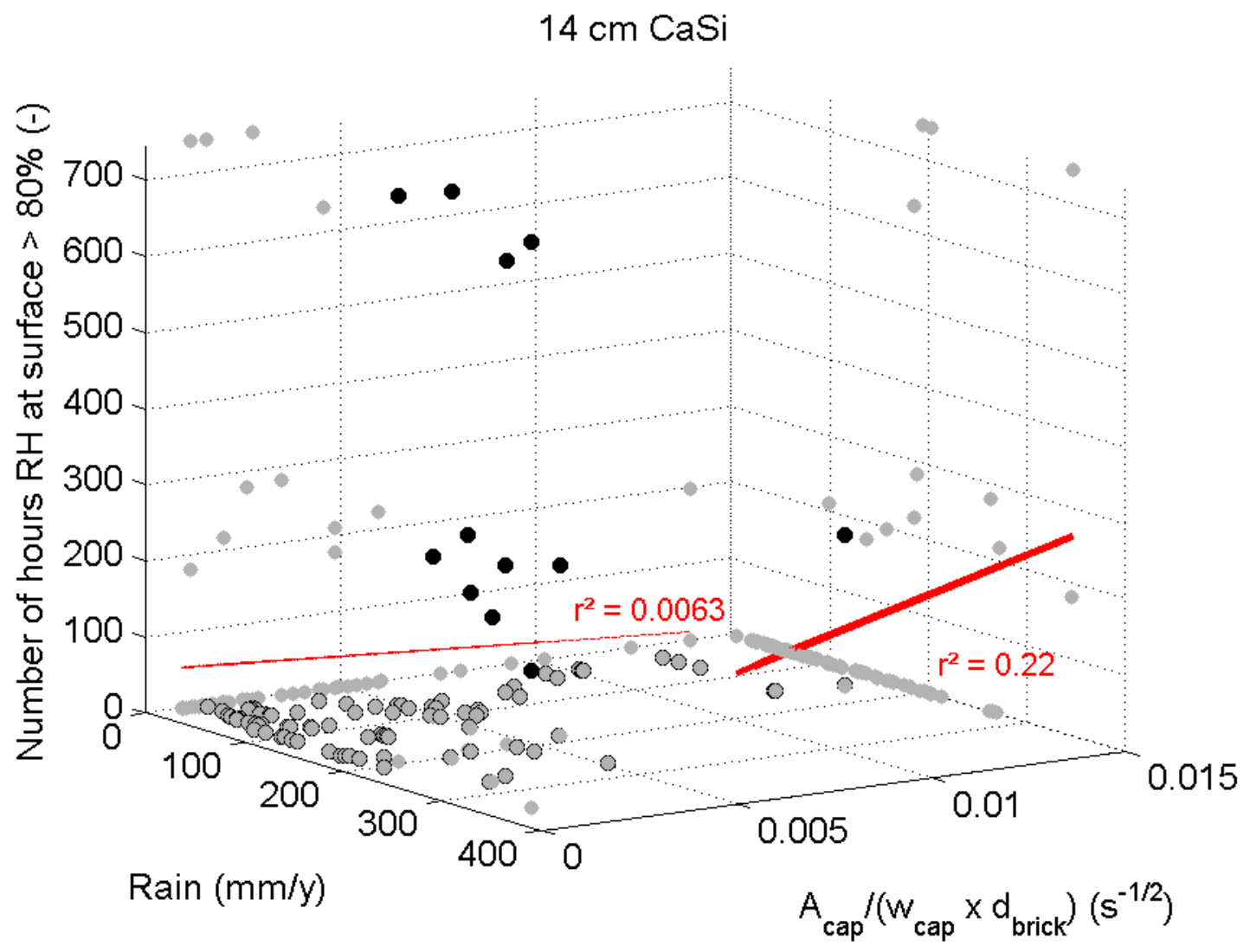


Postprint: Vereecken E, Van Gelder L, Janssen H, Roels S, 2015. Interior insulation for wall retrofitting - A probabilistic analysis of energy savings and hygrothermal risks. Energy and Buildings 89: 231-244. doi.org/10.1016/j.enbuild.2014.12.031

c)

\section{$14 \mathrm{~cm}$ XPS}

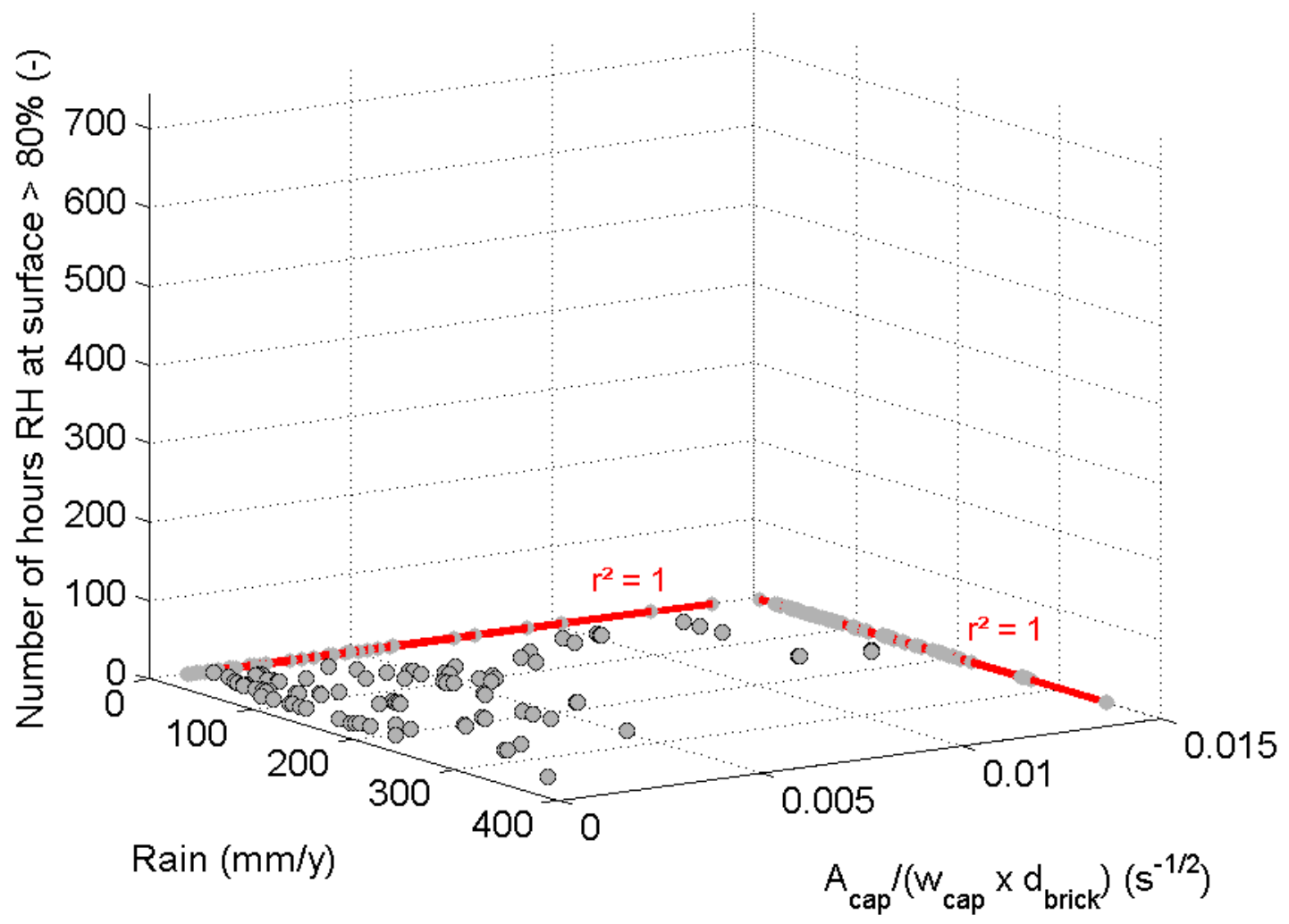


Postprint: Vereecken E, Van Gelder L, Janssen H, Roels S, 2015. Interior insulation for wall retrofitting - A probabilistic analysis of energy savings and hygrothermal risks. Energy and Buildings 89: 231-244. doi.org/10.1016/j.enbuild.2014.12.031

\section{Figure A1}

a)

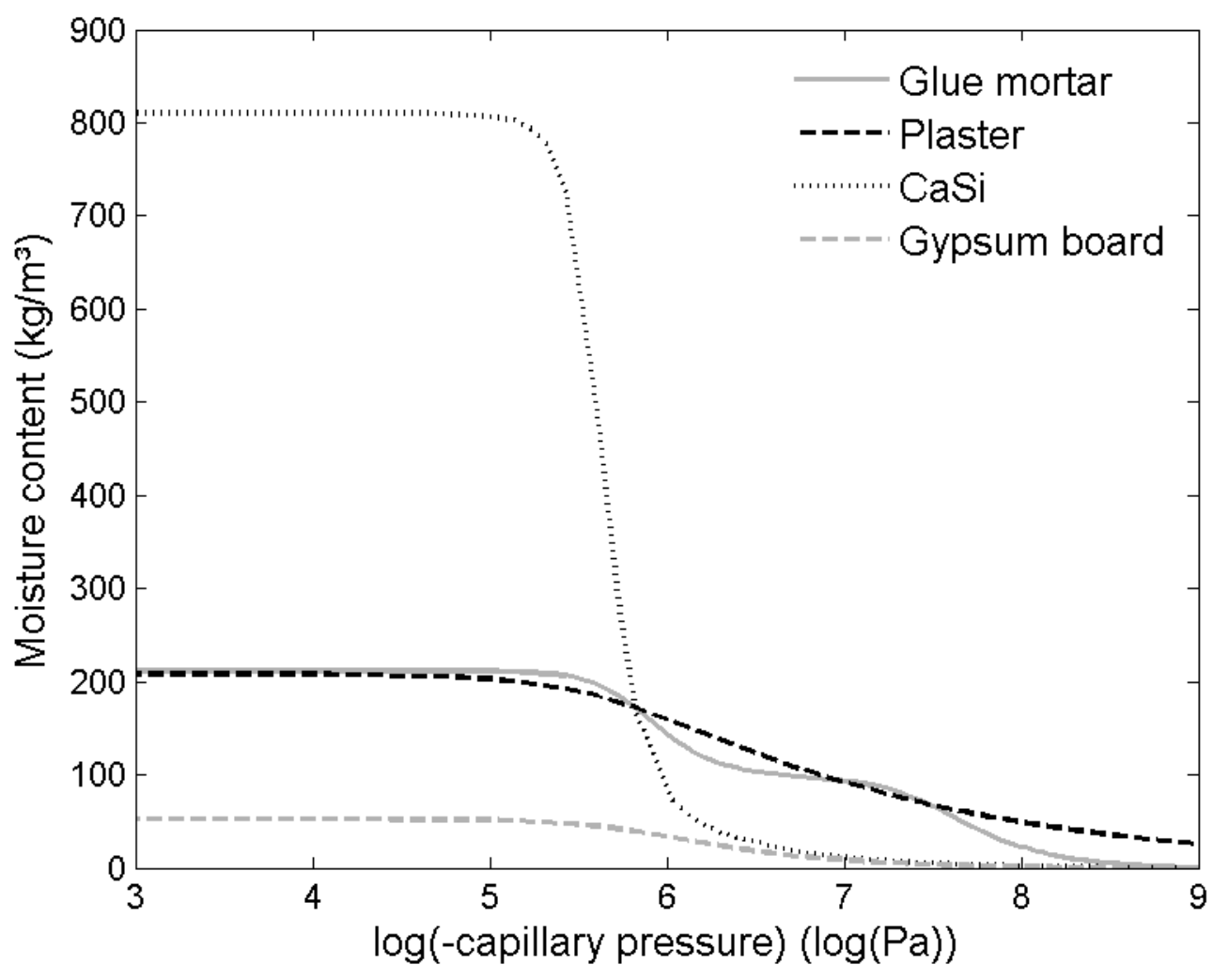


Postprint: Vereecken E, Van Gelder L, Janssen H, Roels S, 2015. Interior insulation for wall retrofitting - A probabilistic analysis of energy savings and hygrothermal risks. Energy and Buildings 89: 231-244. doi.org/10.1016/j.enbuild.2014.12.031

b)

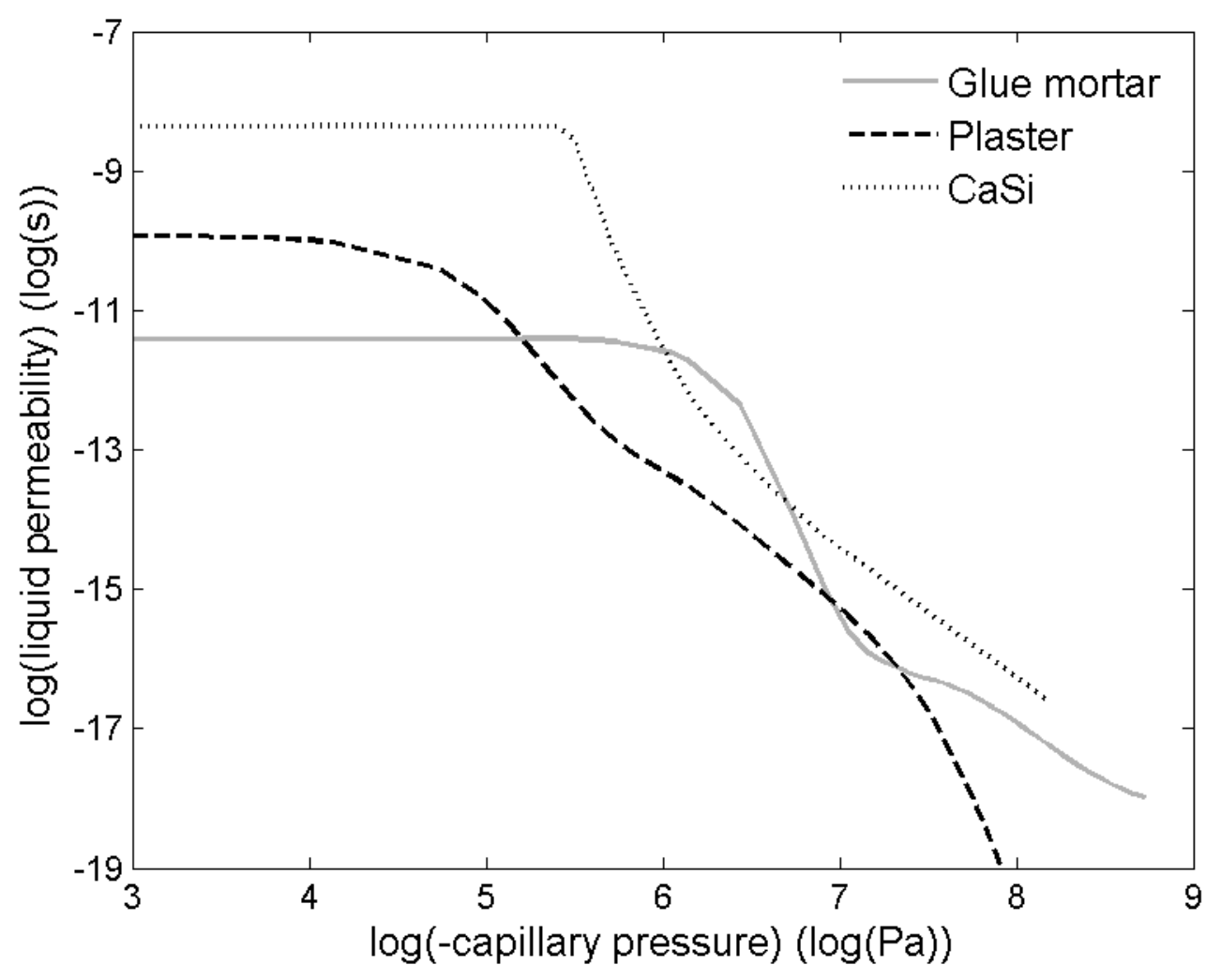


Postprint: Vereecken E, Van Gelder L, Janssen H, Roels S, 2015. Interior insulation for wall retrofitting - A probabilistic analysis of energy savings and hygrothermal risks. Energy and Buildings 89: 231-244. doi.org/10.1016/j.enbuild.2014.12.031

\section{Figure A2}

a)

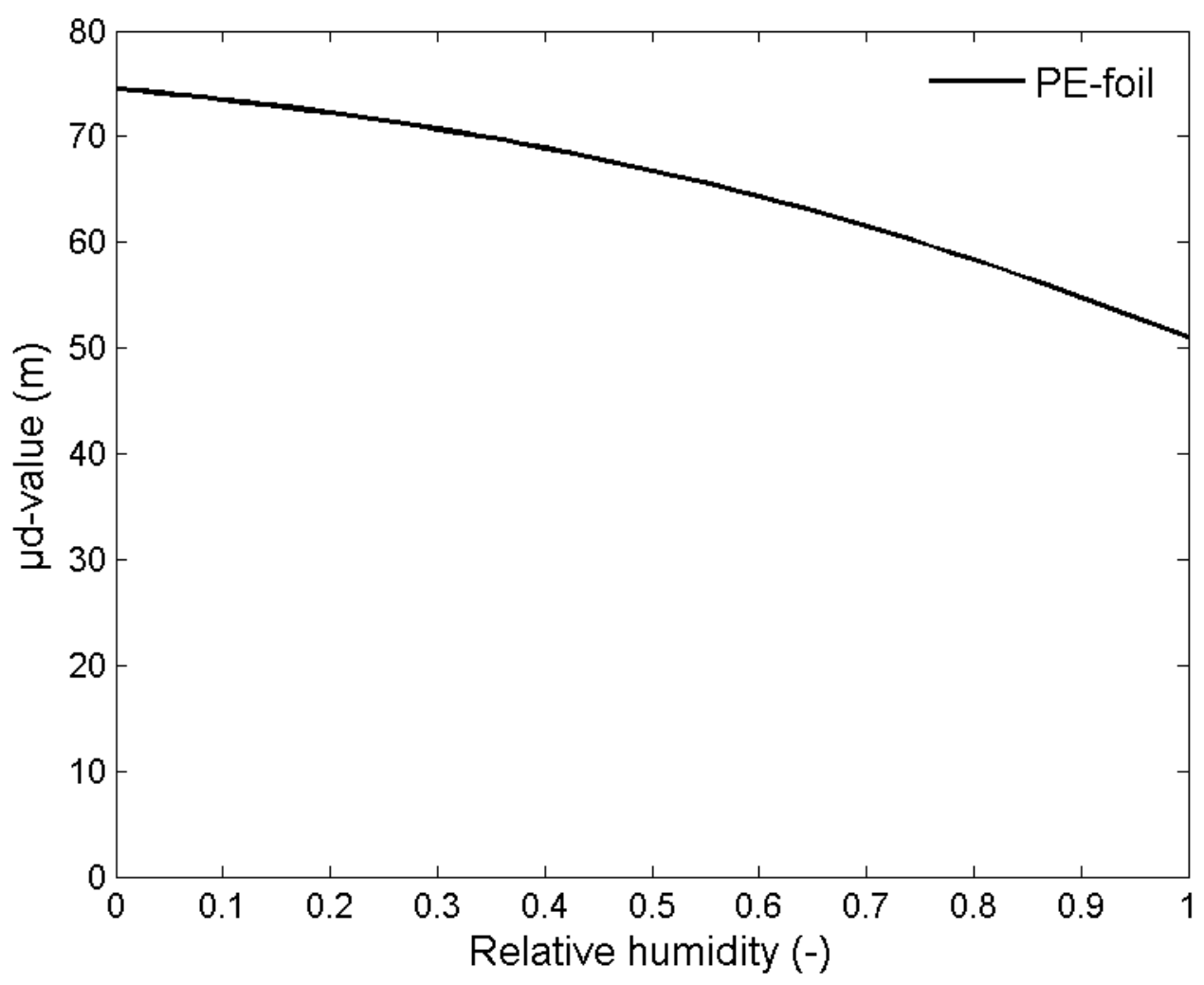


Postprint: Vereecken E, Van Gelder L, Janssen H, Roels S, 2015. Interior insulation for wall retrofitting - A probabilistic analysis of energy savings and hygrothermal risks. Energy and Buildings 89: 231-244. doi.org/10.1016/j.enbuild.2014.12.031

b)

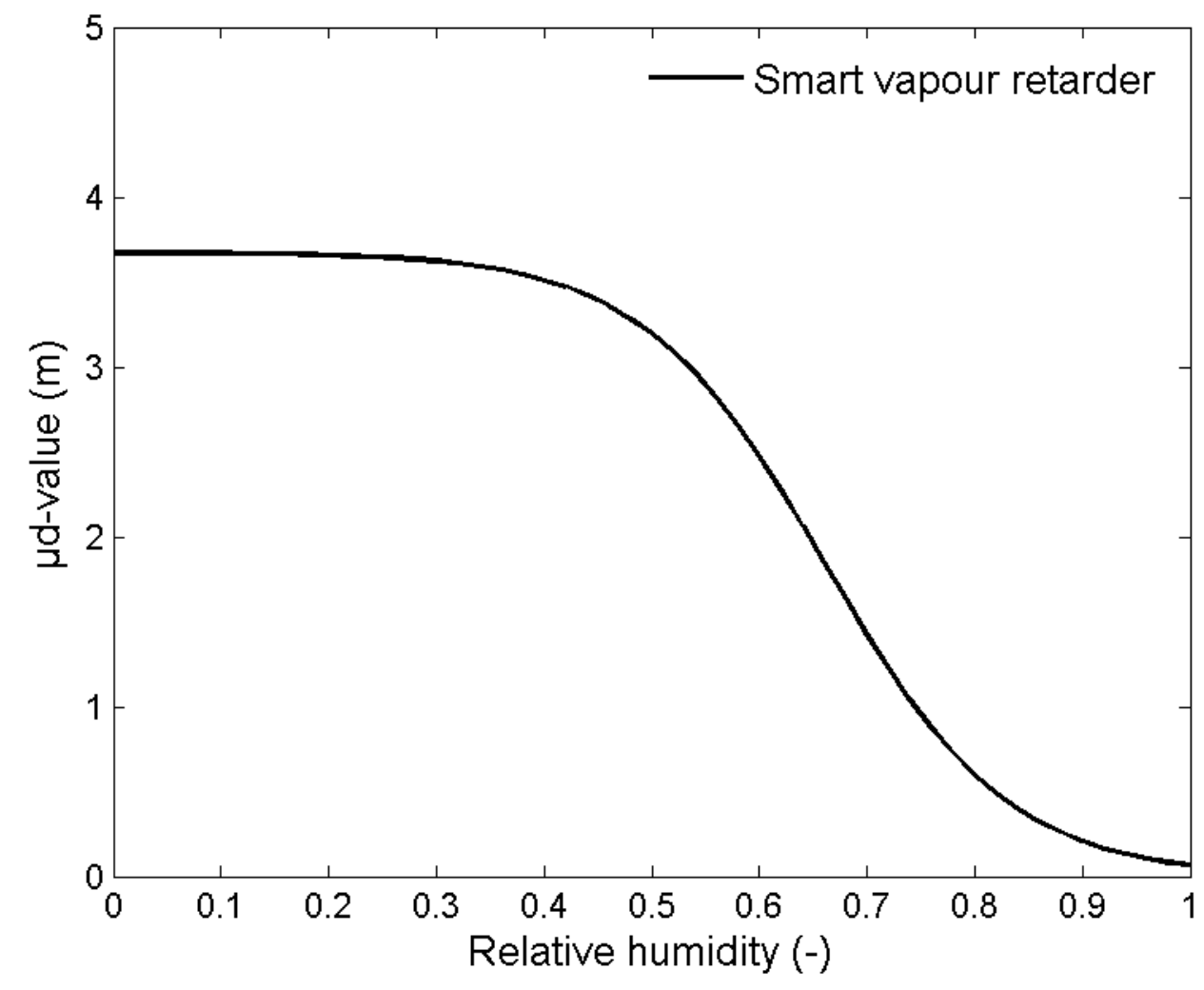




\section{TABLES}

Table 1. Probabilistic parameters and distributions.

\begin{tabular}{|c|c|}
\hline Input parameter & Input distribution ${ }^{(1)}$ \\
\hline \multicolumn{2}{|l|}{ Climatic conditions } \\
\hline Wall conditions & D(Essen, Bremerhaven, München) \\
\hline Wall orientation (degree from North ${ }^{\circ}$ ) & $U(0,360)$ \\
\hline Solar absorption coefficient & $U(0.4,0.8)$ \\
\hline Scale factor catch ratio WDR & $U(0,1.5)$ \\
\hline Windward A-coefficient (used in Eq.(1)) & $U(0,7.2)$ \\
\hline $\begin{array}{l}\text { Leeward A-coefficient (used in Eq.(1)) } \\
\text { Brick layer }\end{array}$ & $U(3.5,1.1)$ \\
\hline Thickness (m) & $U(0.15,0.50)$ \\
\hline $\begin{array}{l}\text { Material } \\
\text { Room conditions }\end{array}$ & $\mathrm{D}($ Brick 1, Brick 2, Brick 3) (see Table 2) \\
\hline Type of room & $\mathrm{D}$ (living room, bedroom) \\
\hline - indoor temperature $\left({ }^{\circ} \mathrm{C}\right)$ & living room $N(20,1.5)$; bedroom $N(17,2)$ \\
\hline - $\quad$ air change rate $(1 / h)$ & $\begin{array}{l}\text { living room } U(75 / V, 150 / V) ; \text { bedroom } \\
U(25 / V, 72 / V)\end{array}$ \\
\hline Floor area $\left(\mathrm{m}^{2}\right)$ & $\cup(9,36)$ \\
\hline Number of persons & $D(1,3)$ \\
\hline Hygric inertia of the room $\left(\mathrm{g} / \mathrm{m}^{3 \%} \% \mathrm{RH}\right)$ & $U(0,3.558)$ \\
\hline \multicolumn{2}{|l|}{ (1) Explanation of symbols used: } \\
\hline \multicolumn{2}{|c|}{$\mathrm{U}(\mathrm{a}, \mathrm{b})$ : uniform distribution between $\mathrm{a}$ and $\mathrm{b}$} \\
\hline \multicolumn{2}{|c|}{$D(a, b)$ : discrete uniform distribution with options $a$ and $b$, } \\
\hline $\mathrm{N}(\mu, \sigma)$ : normal distribution with mean vé & e $\mu$ and standard deviation $\sigma$. \\
\hline
\end{tabular}


Table 2. Properties brick types.

\begin{tabular}{|c|c|c|c|}
\hline Material property & Brick 1 [42] & Brick 2 [43] & Brick 3 [39] \\
\hline Capillary absorption $\left(\mathrm{kg} / \mathrm{m}^{2} \mathrm{~s}^{0.5}\right)^{(1)}$ & 0.125 & 0.46 & 0.04 \\
\hline Bulk density $\left(\mathrm{kg} / \mathrm{m}^{3}\right)$ & 2087 & 1786 & 1980 \\
\hline Thermal capacity (J/kgK) & 870 & 1000 & 834 \\
\hline Dry thermal conductivity $\lambda(\mathrm{W} / \mathrm{mK})$ & 0.9 & 1.08 & 0.996 \\
\hline awet (-) (2) & $4.7 \times 10^{-3}$ & $4.7 \times 10^{-3}$ & $4.7 \times 10^{-3}$ \\
\hline Dry vapour resistance factor (-) & 24.8 & 14.3 & 45.1 \\
\hline Capillary moisture content $\left(\mathrm{kg} / \mathrm{m}^{3}\right)$ & 130 & 206.7 & 101 \\
\hline Saturation moisture content $\left(\mathrm{kg} / \mathrm{m}^{3}\right)$ & 209 & 323 & 253 \\
\hline \multicolumn{4}{|c|}{ (1) Based on a simulated absorption experiment. } \\
\hline \multicolumn{4}{|c|}{$\begin{array}{l}\text { (2) Parameter to include the moisture dependency on the thermal conductivity } \\
\lambda=\lambda_{d r y}+a_{w e t} \cdot w \text {, where } \mathrm{w} \text { the moisture content in } \mathrm{kg} / \mathrm{m}^{3}[44] \text {. }\end{array}$} \\
\hline
\end{tabular}


Postprint: Vereecken E, Van Gelder L, Janssen H, Roels S, 2015. Interior insulation for wall retrofitting - A probabilistic analysis of energy savings and hygrothermal risks. Energy and Buildings 89: 231-244. doi.org/10.1016/j.enbuild.2014.12.031

Table 3. Deterministic boundary conditions.

\begin{tabular}{|ll|}
\hline Input parameter & Input value \\
\hline$\underline{\text { Exterior surface }}$ & 0.9 \\
Long-wave emissivity & $1.54 \times 10^{-7}$ \\
Moisture transfer coefficient $\beta(\mathrm{s} / \mathrm{m})$ & \\
$\underline{\text { Interior surface }}$ & 8 \\
Total heat transfer coefficient $\mathrm{h}\left(\mathrm{W} / \mathrm{m}^{2} \mathrm{~K}\right)$ & $\mathrm{h} / 2 \times 7.7 \times 10^{-9}$ \\
Moisture transfer coefficient $\beta(\mathrm{s} / \mathrm{m})$ & \\
$\underline{\text { Wall assembly }}$ & 20 \\
Initial temperature $\left({ }^{\circ} \mathrm{C}\right)$ & 50 \\
Initial relative humidity $(\%)$ & \\
$\underline{\text { Room conditions }}$ & 2.5 \\
Room height (m)
\end{tabular}


Postprint: Vereecken E, Van Gelder L, Janssen H, Roels S, 2015. Interior insulation for wall retrofitting - A probabilistic analysis of energy savings and hygrothermal risks. Energy and Buildings 89: 231-244. doi.org/10.1016/j.enbuild.2014.12.031

Table 4. Overview of the energy savings and the hygrothermal performance for the studied cases. For each performance criterion, the results that make one of both interior insulation systems less favourable than the other are indicated in red.

\begin{tabular}{|c|c|c|c|c|c|c|c|c|c|}
\hline & Performance criteria & & Reference & $2 \mathrm{~cm} \times P S$ & $14 \mathrm{~cm}$ XPS & $30 \mathrm{~cm}$ XPS & $2 \mathrm{~cm} \mathrm{CaSi}$ & $14 \mathrm{~cm} \mathrm{CaSi}$ & $30 \mathrm{~cm} \mathrm{CaSi}$ \\
\hline \multirow{5}{*}{ Total heat loss } & \multirow{5}{*}{$\begin{array}{l}\text { Total heat loss } \\
\text { (in January) }\end{array}$} & Minimum & 14407 & 6839 & 1849 & 937 & 10095 & 3391 & 1788 \\
\hline & & $25^{\text {th }}$ percentile & 21743 & 9456 & 2581 & 1288 & 14642 & 4930 & 2532 \\
\hline & & Median & 26562 & 10994 & 2887 & 1443 & 17527 & 5649 & 2937 \\
\hline & & $75^{\text {th }}$ percentile & 33861 & 12803 & 3164 & 1594 & 22198 & 8904 & 4495 \\
\hline & & Maximum & 62622 & 16497 & 3975 & 1971 & 45426 & 21030 & 15639 \\
\hline \multirow{5}{*}{ Frost damage } & \multirow{5}{*}{$\begin{array}{l}\text { Number of moist frost } \\
\text { cycles per year } \\
\left(-2^{\circ} \mathrm{C}\right)\end{array}$} & Minimum & 0 & 0 & 0 & 0 & 0 & 0 & 0 \\
\hline & & $25^{\text {th }}$ percentile & 0 & 0 & 0 & 0 & 0 & 0 & 0 \\
\hline & & Median & 0 & 0 & 0 & 0 & 0 & 0 & 0 \\
\hline & & $75^{\text {th }}$ percentile & 0 & 0 & 3 & 3 & 0 & 1 & 1 \\
\hline & & Maximum & 16 & 25 & 28 & 31 & 15 & 9 & 9 \\
\hline \multirow{5}{*}{$\begin{array}{l}\text { Moisture level in } \\
\text { construction } \\
\text { (between masonry } \\
\text { and insulation)* }\end{array}$} & \multirow{5}{*}{$\begin{array}{c}\text { Number of hours RH } \\
\text { warm side masonry > } \\
99.9 \% \text { (in January) }\end{array}$} & Minimum & 0 & 0 & 0 & 0 & 0 & 0 & 0 \\
\hline & & $25^{\text {th }}$ percentile & 0 & 0 & 0 & 0 & 0 & 0 & 0 \\
\hline & & Median & 0 & 0 & 0 & 0 & 0 & 0 & 0 \\
\hline & & $75^{\text {th }}$ percentile & 0 & 342 & 342 & 346 & 0 & 0 & 0 \\
\hline & & Maximum & 744 & 744 & 744 & 744 & 705 & 164 & 182 \\
\hline \multirow{5}{*}{$\begin{array}{l}\text { Moisture level in } \\
\text { construction } \\
\text { (wooden beam } \\
\text { ends) }\end{array}$} & \multirow{5}{*}{$\begin{array}{l}\text { Number of hours RH in } \\
\text { brick }>95 \% \text { (in January) }\end{array}$} & Minimum & 0 & 0 & 0 & 0 & 0 & 0 & 0 \\
\hline & & $25^{\text {th }}$ percentile & 0 & 59 & 312 & 360 & 0 & 63 & 141 \\
\hline & & Median & 148 & 636 & 744 & 744 & 262 & 540 & 727 \\
\hline & & $75^{\text {th }}$ percentile & 744 & 744 & 744 & 744 & 744 & 744 & 744 \\
\hline & & Maximum & 744 & 744 & 744 & 744 & 744 & 744 & 744 \\
\hline \multirow{3}{*}{$\begin{array}{l}\text { RH on the indoor } \\
\text { surface (mould } \\
\text { growth) }\end{array}$} & \multirow{3}{*}{$\begin{array}{l}\text { Number of hours RH } \\
\text { indoor surface }>80 \% \\
\text { (in January) }\end{array}$} & Minimum & 0 & 0 & 0 & 0 & 0 & 0 & 0 \\
\hline & & $25^{\text {th }}$ percentile & 0 & 0 & 0 & 0 & 0 & 0 & 0 \\
\hline & & Median & 0 & 0 & 0 & 0 & 0 & 0 & 0 \\
\hline
\end{tabular}


Postprint: Vereecken E, Van Gelder L, Janssen H, Roels S, 2015. Interior insulation for wall retrofitting - A probabilistic analysis of energy savings and hygrothermal risks. Energy and Buildings 89: 231-244. doi.org/10.1016/j.enbuild.2014.12.031

\begin{tabular}{|c|c|c|c|ccccc} 
& $75^{\text {th }}$ percentile & 0 & 0 & 0 & 0 & 0 & 0 & 0 \\
& Maximum & 744 & 0 & 0 & 0 & 744 & 744 & 744 \\
\hline
\end{tabular}

*For the reference wall, the RH between masonry and plaster is studied. 
Postprint: Vereecken E, Van Gelder L, Janssen H, Roels S, 2015. Interior insulation for wall retrofitting - A probabilistic analysis of energy savings and hygrothermal risks. Energy and Buildings 89: 231-244. doi.org/10.1016/j.enbuild.2014.12.031

Table A.1. Material properties insulation systems and interior finishing layers.

\begin{tabular}{|c|c|c|c|c|c|c|}
\hline Material property & XPS & CaSi & $\begin{array}{l}\text { Glue } \\
\text { mortar }\end{array}$ & MW & $\begin{array}{l}\text { Gypsum } \\
\text { board }\end{array}$ & plaster \\
\hline Bulk density $\left(\mathrm{kg} / \mathrm{m}^{3}\right)$ & 88 & 270 & 1680 & 42 & 690 & 790 \\
\hline $\begin{array}{l}\text { Thermal capacity } \\
(\mathrm{J} / \mathrm{kgK})\end{array}$ & 840 & 1000 & 1000 & 840 & 1090 & 870 \\
\hline $\begin{array}{l}\text { Dry thermal } \\
\text { conductivity }(\mathrm{W} / \mathrm{mK})\end{array}$ & 0.033 & 0.06 & 0.7 & 0.033 & 0.198 & 0.2 \\
\hline awet $(-)^{(1)}$ & 0 & $5.6 \times 10^{-4}$ & 0 & 0 & 0 & $4.5 \times 10^{-3}$ \\
\hline $\begin{array}{l}\text { Dry vapour } \\
\text { resistance factor (-) }\end{array}$ & 200 & 5.6 & 32 & 1.2 & 1.23 & 3 \\
\hline $\begin{array}{l}\text { Capillary moisture } \\
\text { content }\left(\mathrm{kg} / \mathrm{m}^{3}\right)\end{array}$ & $\approx 0$ & 811.6 & 212.3 & 0.83 & 53.13 & 209 \\
\hline \multicolumn{7}{|c|}{$\begin{array}{l}\text { (1) Parameter to include the } \mathrm{m} \\
\text { moisture content in } \mathrm{kg} / \mathrm{m}^{3} \text { [44]. }\end{array}$} \\
\hline
\end{tabular}


Postprint: Vereecken E, Van Gelder L, Janssen H, Roels S, 2015. Interior insulation for wall retrofitting - A probabilistic analysis of energy savings and hygrothermal risks. Energy and Buildings 89: 231-244. doi.org/10.1016/j.enbuild.2014.12.031 